\title{
A systematic review on the use of quantitative imaging to detect cancer therapy adverse effects in normal-appearing brain tissue
}

\author{
Jan Petr ${ }^{1,2}\left(\right.$ D Louise Hogeboom ${ }^{2} \cdot$ Pavel Nikulin $^{1} \cdot$ Evita Wiegers $^{3} \cdot$ Gwen Schroyen $^{4} \cdot$ Jesper Kallehauge $^{5}$. \\ Marek Chmelík $^{6} \cdot$ Patricia Clement $^{7} \cdot$ Ruben E. Nechifor $^{8} \cdot$ Liviu-Andrei Fodor $^{9} \cdot$ Philip C. De Witt Hamer $^{10}$. \\ Frederik Barkhof ${ }^{2,11} \cdot$ Cyril Pernet $^{12} \cdot$ Maarten Lequin $^{3} \cdot$ Sabine Deprez $^{4} \cdot$ Radim Jančálek $^{13}$. \\ Henk J. M. M. Mutsaerts ${ }^{2,7} \cdot$ Francesca B. Pizzini $^{14} \cdot$ Kyrre E. Emblem $^{15} \cdot$ Vera C. Keil $^{2}$
}

Received: 21 July 2021 / Revised: 9 November 2021 / Accepted: 3 December 2021 / Published online: 17 December 2021 (c) The Author(s) 2021

\begin{abstract}
Cancer therapy for both central nervous system (CNS) and non-CNS tumors has been previously associated with transient and long-term cognitive deterioration, commonly referred to as 'chemo fog'. This therapy-related damage to otherwise normalappearing brain tissue is reported using post-mortem neuropathological analysis. Although the literature on monitoring therapy effects on structural magnetic resonance imaging (MRI) is well established, such macroscopic structural changes appear relatively late and irreversible. Early quantitative MRI biomarkers of therapy-induced damage would potentially permit taking these treatment side effects into account, paving the way towards a more personalized treatment planning. This systematic review (PROSPERO number 224196) provides an overview of quantitative tomographic imaging methods, potentially identifying the adverse side effects of cancer therapy in normal-appearing brain tissue. Seventy studies were obtained from the MEDLINE and Web of Science databases. Studies reporting changes in normal-appearing brain tissue using MRI, PET, or SPECT quantitative biomarkers, related to radio-, chemo-, immuno-, or hormone therapy for any kind of solid, cystic, or liquid tumor were included. The main findings of the reviewed studies were summarized, providing also the risk of bias of each study assessed using a modified QUADAS-2 tool. For each imaging method, this review provides the methodological background, and the benefits and shortcomings of each method from the imaging perspective. Finally, a set of recommendations is proposed to support future research.
\end{abstract}

Keywords Neuroimaging $\cdot$ Radiotherapy $\cdot$ Chemotherapy $\cdot$ Long-term adverse effects $\cdot$ Cognitive decline

\section{Introduction}

Cancer therapy is associated with a multitude of adverse effects such as cognitive dysfunction and a lower quality of life. These effects most likely have a multifactorial origin and are associated with several components of the treatment. For example, the use of brain radiotherapy (RTx) [1] and various chemotherapy (CTx) agents in both central nervous system (CNS) and non-CNS cancer are associated with normal tissue damage in the brain and subsequent cognitive decline $[2,3]$. Despite a co-factoring genetic predisposition $[4,5]$, the amount of damage and related cognitive deterioration from cancer therapy cannot yet be predicted on

Jan Petr

j.petr@hzdr.de

Extended author information available on the last page of the article an individual level [6], and the cellular mechanisms behind these changes are not well understood. Non-invasive biomarkers of treatment response to cancer therapy in normalappearing brain tissue (NABT) are thus needed to (i) study the etiology of damage and (ii) obtain early-markers of tissue damage, allowing timely adjustment of the treatment or start of supportive therapy to reduce the risks of associated long-term cognitive and quality-of-life deterioration. Effects on cognition and quality of life become increasingly important issues as new therapies for cancer in the body lead to prolonged survival with cerebral oligometastatic conditions kept stable also due to focused radiotherapy.

Currently, brain imaging research of cancer-therapy adverse effects is primarily focused on changes in brain tissue composition [7] measured with T1-weighted, T2-weighted, FLAIR, and susceptibility-weighted imaging (SWI) sequences. These sequences are conventionally 
used in the clinical context of tumors, are more studied in the context of adverse effects in normal tissues, and were reviewed several times. More specifically, dose-related changes in gray matter (GM) volume and thickness have been documented a few months after RTx in CNS $[8,9]$ and CTx in non-CNS cancer [10]. Susceptibility of different brain structures to damage and exact dose tolerance are, however, still unknown [11]. Moreover, cognitive decline after RTx has been associated with microvascular damage [12]. These are hallmarks of vascular-related cognitive changes, typically observed in dementia, and their appearance after RTx points to similarities with neurodegenerative diseases in an accelerated form. Structural changes in white matter (WM), measured with diffusion tensor imaging, have also shown a decrease in fractional anisotropy, potentially reflecting a decrease in fiber density and myelin content, after CTx in breast cancer, associated with cognitive decline [13]. Similar findings after CTx in acute lymphoblastic leukemia [14], and after RTx in CNS tumors [15] are also reported. Since diffusion tensor imaging (DTI) and functional MRI (fMRI) have been used clinically in the context of brain surgery-mapping the networks that need to be kept intact - these sequences have also been reviewed several times for their ability to pick up treatment-induced brain changes [11, 13, 14, 16, 17].

To complement these existing reviews of conventional MRI biomarkers, we set out to review new quantitative imaging biomarkers that are usually not part of the clinical tumor workup. These imaging sequences, measuring physiology and metabolism, may provide early markers of treatment damage, yet, they are usually not considered for evaluation of cancer therapy side effects [18]. The common reasons for this are a lack of insight into the biological specificity of these advanced sequences, the limited available scanning time beyond the standard protocol, and the fact that the complexity of some of these protocols makes them unfit for some of the patients. Insufficient clinical implementation [19], due to difficult acquisition and analysis, often leads to low levels of evidence in this context [20]. To trigger change, more attention needs to be devoted to these techniques, starting by reviewing the current body of literature.

This systematic review explores the current level of knowledge on quantitative imaging techniques for perfusion, metabolism, relaxometry, spectroscopy, advanced diffusion, and susceptibility imaging to evaluate longitudinal alterations in the NABT, in the sense of a visual absence of the tumor, due to both CNS and non-CNS cancer treatment in participants of all sexes and ages. It also assesses the correlation of cross-sectional and longitudinal changes obtained using quantitative measurements with cognitive function changes.

\section{Methods}

This systematic review was registered at PROSPERO number 224196 and followed the PRISMA and PRISMA-P guidelines [21, 22]. The literature search was based on the PICOS tool [23]. The protocols are included in Supplementary Materials.

\section{Literature search and selection}

Briefly, the structure of the search term was

- Neoplasm: e.g., liquid tumors, body tumors, CNS tumors, cancer;

- Normal tissue effect: e.g., normal brain, adverse effects, cognitive impairment;

- Neuroimaging: e.g., MRI, advanced MRI, Positron emission tomography (PET);

- Cancer therapy: e.g., RTx, immunotherapy, CTx, hormone therapy.

The exact search strategy is provided in Supplementary Materials and PICOS. Two databases were searched-Medical Literature Analysis and Retrieval System Online (MEDLINE) through PubMed search engine, and Web of Science core collection-on October 13, 2021, without restriction on publication date.

Two reviewers (JP and VK) sorted all publications by titles into four categories and reassessed them in a consensus meeting:

- A-Fits most likely with the inclusion/exclusion criteria (Table 1);

- B-Reasonable chance that part of data fits with the inclusion/exclusion criteria;

- C-Unlikely to contain data on the review subject, but no clear exclusion criteria;

- D-Exclusion criteria identified or clearly a different topic.

Studies in categories $\mathrm{D}$ were excluded based on title only. Studies in groups A, B, C were reassessed for compliance with the inclusion and exclusion criteria by screening their abstracts. The full text was consulted in unclear cases (Fig. 1).

\section{Critical appraisal}

To assess the quality of the included studies, the QUADAS-2 tool [24] was modified to assess observational imaging 
Table 1 Inclusion and exclusion criteria

\begin{tabular}{|c|c|}
\hline Inclusion criteria & Exclusion criteria \\
\hline $\begin{array}{l}\text { Human patients of all ages and sexes } \\
\text { Longitudinal data before and after treatment OR cross-sectional } \\
\text { design with an appropriate control group or a different treatment arm } \\
\text { that allows evaluating the treatment effects after treatment } \\
\text { Present or past neoplasia anywhere in the body } \\
\text { Local or systemic treatment by RTx, CTx, or hormone therapy } \\
\text { Advanced quantitative computed tomography, MRI (i.e. ASL, } \\
\text { CEST, DCE, DSC, DKI, IVIM, mcDESPOT, MRS, MRSI, MWI, } \\
\text { NODDI, qMT, QSM, relaxometry, VERDICT), PET/SPECT (DOPA, } \\
\text { FDG, TRODAT, HMPAO, TSPO, 15O-H2O) imaging in the brain } \\
\text { Dedicated description of imaging findings in NABT as a reaction to } \\
\text { cancer treatment }\end{array}$ & $\begin{array}{l}\text { Not an original research article (e.g. review, conference proceedings, } \\
\text { case study, protocol) } \\
\text { Preclinical research } \\
\text { Animal research } \\
\text { Language other than English } \\
\text { Study containing results only from structural MRI (e.g. DWI, DTI, } \\
\text { brain volumetry, T1w, T2w, FLAIR, STI, SWI) or functional MRI } \\
\text { Findings are reported in normal tissue only in close vicinity of the } \\
\text { tumor }\end{array}$ \\
\hline
\end{tabular}

Publications that fulfill all inclusion criteria and neither exclusion criteria were considered. Publications containing additional results to advanced imaging of normal tissue — e.g. extra structural imaging, tumor imaging-were considered

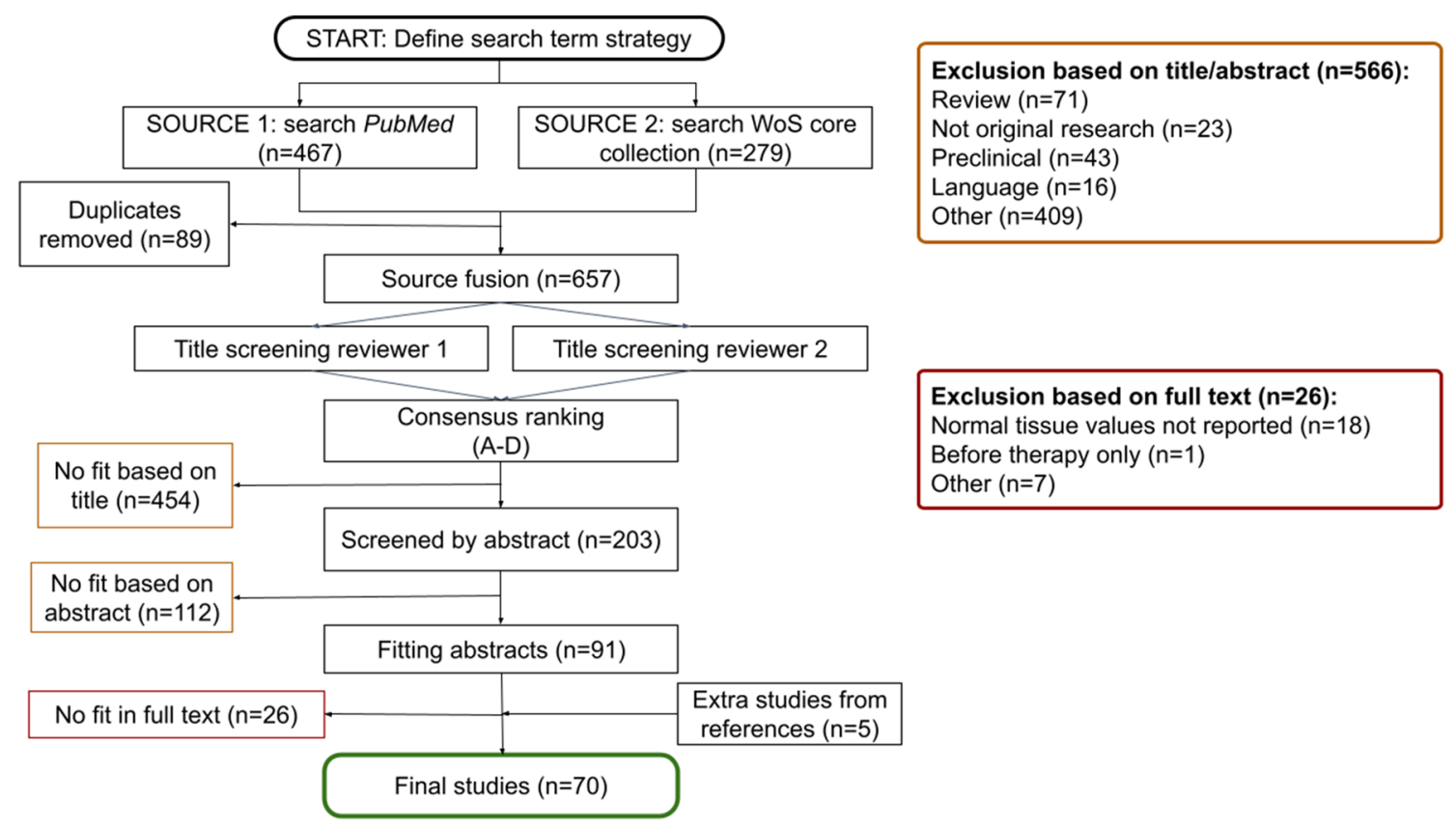

Fig. 1 Workflow of the study search and selection. Two databases were searched using the predefined search strategy-MEDLINE, Medical Literature Analysis and Retrieval System Online (PubMed), and Web of Science database (WoS). After excluding the duplicates

studies (Table 2). This modified QUADAS-2 tool represents a list of questions from five different domains that represent the "risk of bias" associated with each study. Complete details and guidelines for scoring can be found in the Supplementary material.

\section{Data extraction}

Bibliography, patient demographics, tumor type and grade, therapy type (RTx, CTx, hormone, immunotherapy, the studies were initially screened by title (excluding $n=446$ studies), abstract (excluding $n=96$ studies), and full text (excluding $n=25$ studies), leaving 60 studies. Six more studies were discovered by screening the reference sections of selected studies

or other therapies) and doses, imaging modality and sequence, modified QUADAS-2 score, timeline of imaging, a summary of main imaging findings, and association with cognition and QoL were extracted from each study. The following notation was used for reporting the timing of the adverse effect:

- TS - time of surgery/biopsy before the start of treatment

- T0_baseline measurement before the start of the RCTx/ immuno/hormone therapy 
Table 2 Modified QUADAS-2 tool

\begin{tabular}{ll}
\hline QUADAS domain & Risk of bias questions \\
\hline Domain 1: Patient selection & $\begin{array}{l}\text { Study design (retrospective vs pro- } \\
\text { spective) } \\
\text { Patient selection } \\
\text { Clear description of selection criteria } \\
\text { Case description }\end{array}$ \\
& $\begin{array}{l}\text { Image acquisition description } \\
\text { Image analysis description }\end{array}$ \\
Domain 2: Index test & $\begin{array}{l}\text { Region of interest and data extraction } \\
\text { Tumor classification quality } \\
\text { Doman 3: Reference test }\end{array}$ \\
Treatment details description \\
Domain 4: Flow and timing & $\begin{array}{l}\text { Timing of treatment and imaging } \\
\text { described }\end{array}$ \\
Domain 5: Data analysis, & Withdrawals and exclusions explained \\
processing, and reporting & $\begin{array}{l}\text { Statistical tests reported and sufficient } \\
\text { Data availability }\end{array}$
\end{tabular}

The quality of the reporting for each study was assessed in five domains. For each domain, one to three aspects were scored as having low, medium, or high risk of bias. A detailed explanation is provided in Supplementary Materials

- T1-acute effects during therapy or until 1 month $\underline{\text { after }}$ the therapy start

- T2-early delayed effects at 1-6 months after the therapy end

- T3-late-delayed effects at more than 6 months after the therapy end

Co-authors were assigned so that each modality would be reviewed by the same person-DSC (KE), DCE (JK), ASL (LH), DKI (JK), relaxometry (RN), QSM/ qMT/NODDI (VK), PET/SPECT (PN), MRS (MC, RJ, GS, EW). For papers with more than one modality, the imaging data were reviewed separately for each modality by the relevant reviewers and non-imaging data were reviewed by only one of the reviewers. Non-imaging data from pediatric studies (ML, EW) and breast cancer studies (SD, GS) were extracted separately. Cognitive tests and QoL were assessed separately by (LAF, FBP, and $\mathrm{CP})$. All entries were verified by one co-author (JP). The studies were reviewed, scored, and summarized focusing on the level of evidence for finding tissue damage in different methods and methodological issues that could explain heterogeneous findings. Also, the correlation of the imaging changes with changes revealed using cognitive testing was reviewed. QUADAS scores and extracted data were filled in an online Google-Sheet to allow all coauthors to fill the data in parallel and prevent conflicting entries, especially for publications containing results for multiple sequences.

\section{Results}

The search resulted in 746 records of which 70 studies were eligible for review (Fig. 1).

\section{Perfusion imaging}

Animal studies have shown that acute vascular injury after radiotherapy leads to vessel dilation and damage of the vessel endothelium $[25,26]$. This is followed by thrombi causing microvascular occlusions [27] as a possible trigger for WM-lesion formation [28]. However, a potentially more sensitive marker of microvascular damage is perfusion imaging, comprising methods with and without exogenous tracers: single-photon emission computed tomography (SPECT), PET, dynamic susceptibility contrast (DSC), dynamic contrast-enhanced (DCE), and arterial spin labeling (ASL) MRI. SPECT and PET use ${ }^{99} \mathrm{Tc}-\mathrm{HMPAO}$ and ${ }^{15} \mathrm{O}-$ $\mathrm{H}_{2} \mathrm{O}$ radiotracers, the latter being the gold standard in cerebral perfusion imaging. However, ${ }^{15} \mathrm{O}-\mathrm{H}_{2} \mathrm{O}$ PET is costly and clinically impractical due to the short tracer half-life and the need for arterial blood sampling. More clinically feasible are dynamic gadolinium-based MRI measurements focusing on changes in T2* (DSC) or T1 (DCE) relaxation. The main advantage of DSC is its widespread use [19] with contrast agents available as part of the routine application for most MRI tumor protocols. DSC may, however, underestimate perfusion in the absence of an intact BBB. In contrast, DCE is a widely used technique to assess apparent contrast agent extravasation across BBB but is less sensitive in regions with an intact BBB. The main challenge to both DSC and DCE is the limited reproducibility of arterial input function estimation, rendering the perfusion measurement semi-quantitative only [29]. ASL perfusion MRI addresses most of these issues as it is non-invasive using magnetically labeled blood as an endogenous tracer. ASL is fully quantitative with accuracy and reproducibility [30] comparable to ${ }^{15} \mathrm{O}-\mathrm{H}_{2} \mathrm{O}-\mathrm{PET}$ [31]. One disadvantage of ASL is its limited SNR and low sensitivity in regions with low CBF such as the white matter.

The review contains 28 studies on perfusion imaging: PET/SPECT $(n=4)$, DSC $(n=11)$, DCE $(n=5)$, ASL $(n=9)$ imaging. Results are summarized in Table 3 and the modified QUADAS-2 scores are in Supplementary Table 1.

\section{Positron emission and single-photon emission tomographies (PET/SPECT)}

Cerebral blood flow (CBF) decreases were observed at low radiation dose: by 4-7\% (absolute CBF, 2-5 Gy at 2 weeks and 3 months after stereotactic radiosurgery (SRS) [32]) 
Table 3 Perfusion results

\begin{tabular}{|c|c|c|c|c|c|c|}
\hline Study & Modality/MRI field & $\begin{array}{l}\text { Number/female } \\
(\text { age } \pm \text { SD y) }\end{array}$ & $\begin{array}{l}\text { Tumor Type/WHO } \\
\text { grade }\end{array}$ & Treatment & Imaging & Main finding \\
\hline Bian [39] & $3 \mathrm{~T}$ & $18 / 8 \mathrm{~F}(44 \pm 12)$ & HGG III-IV & $\begin{array}{l}\text { IMRTx } 60 \mathrm{~Gy}, \\
\text { TMZ } 75 \text { mg/m2 }\end{array}$ & DSC & $\begin{array}{l}\text { CBV } \downarrow \text { after } 1 \mathrm{y} \text { in } \\
\text { corpus callosum } \\
\text { vs T0 }\end{array}$ \\
\hline Fahlström [43] & $1.5 \mathrm{~T}$ & $10 / ? F(59 \pm 8)$ & HGG III-IV & $\begin{array}{l}\text { IMRTx } 60 \mathrm{~Gy}, \\
\text { TMZ } 75 \mathrm{mg} / \mathrm{m} 2\end{array}$ & DSC & $\begin{array}{l}\text { CBV } \downarrow 4.6-6.7 \%, \\
\text { CBF } \downarrow 5.1-12.5 \% \\
\text { in } \mathrm{GM} \text { at } 1 \mathrm{~m} \\
\text { vs }<5 \mathrm{~Gy}, \mathrm{~T} 0\end{array}$ \\
\hline Fuss [37] & $1.5 \mathrm{~T}$ & $25 / 7 \mathrm{~F}(41 \pm ?)$ & LGG II & $\begin{array}{c}\text { RTx } 60 \mathrm{~Gy} \text {, DXM } \\
1.5-8 \mathrm{mg} / \text { day }\end{array}$ & DSC & $\begin{array}{l}\mathrm{CBV} \downarrow 30 \% \\
\text { for }>24 \mathrm{~Gy} \text { after } \\
1.5-24 \mathrm{~m} \text { vs T0 }\end{array}$ \\
\hline Jakubovic [40] & $1.5 \mathrm{~T}$ & $19 / 9 \mathrm{~F}(? \pm ?)$ & Metastasis & SRS 16-24 Gy & DSC & $\begin{array}{c}\mathrm{CBV} \uparrow 43 \%, \mathrm{CBF} \uparrow \\
34 \% \text { after } 1 \mathrm{~m} \text { in } \\
5-10 \text { Gy vs } \mathrm{T} 0\end{array}$ \\
\hline Lee [41] & $1.5 \mathrm{~T}$ & $22 / 9 F(49 \pm ?)$ & HGG III-IV & RTx 60 Gy & DSC & $\begin{array}{l}\mathrm{CBV} \downarrow \text { non-signifi- } \\
\text { cant vs T0 }\end{array}$ \\
\hline Nilsen [44] & $3 \mathrm{~T}$ & $40 / 24 \mathrm{~F}(63 \pm ?)$ & Metastasis & SRS 15-21 Gy & DSC & $\begin{array}{l}\text { CBF, CBV } \downarrow 5 \%, \\
\text { vessel caliber } \uparrow 5 \% \\
\text { after } 6-9 \mathrm{~m} \text { vs T0 }\end{array}$ \\
\hline Price [38] & $3 \mathrm{~T}$ & 3/1F (? $\pm ?)$ & LGG II & RTx 54 Gy & DSC & $\begin{array}{l}\mathrm{CBV} \downarrow 16-21 \%, \\
\mathrm{CBF} \downarrow \text { in } \\
\mathrm{WM}>33 \text { Gy vs T0 }\end{array}$ \\
\hline Singh [45] & $3 \mathrm{~T}$ & $25 / 11 \mathrm{~F}(55 \pm ?)$ & recGBM IV & $\begin{array}{l}\text { BEV escalating } \\
2-15 \mathrm{mg} / \mathrm{kg}\end{array}$ & DSC & $\begin{array}{l}\leftrightarrow \mathrm{CBF}, \mathrm{CBV} \text { in } \\
\text { WM after 6-12 m } \\
\text { vs T0 }\end{array}$ \\
\hline Stadlbauer [46] & $3 \mathrm{~T}$ & $\begin{array}{l}18 / 8 \mathrm{~F}(54 \pm 11) \\
18 / 6 \mathrm{~F}(53 \pm 15)\end{array}$ & recGBM IV & $\begin{array}{l}\mathrm{BEV} 10 \mathrm{mg} / \mathrm{kg} \\
\text { No BEV }\end{array}$ & DSC & $\begin{array}{l}\text { CBV } \downarrow 20-30 \% \text { after } \\
3 \mathrm{~m}, 7 \mathrm{~m} \text { vs T0 and } \\
\text { vs no-BEV }\end{array}$ \\
\hline Weber [42] & $1.5 \mathrm{~T}$ & $25 / 11 \mathrm{~F}(57 \pm ?)$ & Metastasis & SRS 16-20 Gy & DSC & $\begin{array}{r}\leftrightarrow \mathrm{CBF} \text { in } \mathrm{WM} / \mathrm{GM} \\
\text { after } 1.5-6 \mathrm{~m} \text { vs } \mathrm{T} 0\end{array}$ \\
\hline Wenz [36] & $1.5 \mathrm{~T}$ & $\begin{array}{l}19 / 3 \mathrm{~F}(40 \pm 12) \\
13 / 3 \mathrm{~F}(56 \pm 9)\end{array}$ & $\begin{array}{l}\text { LGG II } \\
\text { Metastasis }\end{array}$ & $\begin{array}{l}\text { CRTx } 60 \text { Gy } \\
\text { WBRTx 30-40 Gy }\end{array}$ & DSC & $\begin{array}{l}\mathrm{CBV} \downarrow 30 \% \text { in } \mathrm{WM} \\
\text { and } \mathrm{GM} \text { after } 6 \mathrm{~m} \\
\text { vs T0 }\end{array}$ \\
\hline Andre [54] & $1.5 / 3 \mathrm{~T}$ & 18/8F (57 $\pm ?)$ & recGBM IV & $\begin{array}{l}\text { RTx } 60 \text { Gy, TMZ, } \\
\text { BEV 7.5-10 mg/ } \\
\text { kg }\end{array}$ & pCASL & $\begin{array}{l}\text { Acute } \mathrm{CBF} \downarrow 13 \% \text { in } \\
\text { MCA region vs T0 }\end{array}$ \\
\hline \multirow[t]{2}{*}{ Chen [55] } & \multirow[t]{2}{*}{$3 \mathrm{~T}$} & $31 / 31 \mathrm{~F}(47 \pm 5)$ & Breast II-III & $\begin{array}{r}\text { DXR 60, CP 600, } \\
\text { DTX } 100 \mathrm{mg} / \mathrm{m}\end{array}$ & \multirow[t]{2}{*}{ pCASL } & \multirow[t]{2}{*}{$\begin{array}{l}\mathrm{CBF} \uparrow 7-12 \% \text { after } \\
1 \mathrm{~m} \text { vs T0 and } \mathrm{HC}\end{array}$} \\
\hline & & $34 / 34 \mathrm{~F}(46 \pm 4)$ & $\mathrm{HC}$ & No & & \\
\hline \multirow[t]{3}{*}{ Li [53] } & \multirow[t]{3}{*}{$3 \mathrm{~T}$} & 21/4F (14 $\pm ?)$ & MB IV & $\begin{array}{l}\text { RTx } 55 \text { Gy, CPT, } \\
\text { CP }\end{array}$ & \multirow[t]{3}{*}{ pCASL } & \multirow{3}{*}{$\begin{array}{l}\mathrm{CBF} \downarrow \text { up to } 23 \% \\
\text { after } 0.3-15 \mathrm{y} \text { vs } \mathrm{HC} \\
\text { and PA group }\end{array}$} \\
\hline & & $18 / 9 \mathrm{~F}(12 \pm ?)$ & PA I & No & & \\
\hline & & $64 / 41 \mathrm{~F}(12 \pm ?)$ & $\mathrm{HC}$ & No & & \\
\hline \multirow[t]{3}{*}{ Nudelman [56] } & \multirow[t]{3}{*}{$3 \mathrm{~T}$} & $27 / 27 \mathrm{~F}(50 \pm 8)$ & Breast I-III & $\begin{array}{l}\text { RTx 2, DXR 11, } \\
\text { CP,DTX, HTx } 3\end{array}$ & PASL & \multirow{3}{*}{$\begin{array}{l}\mathrm{CBF} \uparrow 7-12 \% \text { after } \\
1 \mathrm{~m} \text { vs CTx- and } \\
\mathrm{HC} \text { group; } \mathrm{CBF} \uparrow \\
35 \% \text { in CTx }+, \\
\mathrm{CBF} \uparrow 13 \% \text { in } \mathrm{CTx}- \\
\text { both in precentral } \\
\text { gyrus vs HC }\end{array}$} \\
\hline & & 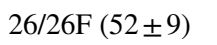 & Breast 0-II & RTx 6, HTx & & \\
\hline & & $26 / 26 \mathrm{~F}(48 \pm 10)$ & $\mathrm{HC}$ & No & & \\
\hline \multirow[t]{2}{*}{ Nudelman [57] } & $3 \mathrm{~T}$ & $24 / 24 \mathrm{~F}(49 \pm 8)$ & Breast I-III & $\begin{array}{l}\text { RTx 2, DXR 11, } \\
\text { CP, DTX, HTx }\end{array}$ & PASL & \multirow{2}{*}{$\begin{array}{l}\mathrm{CBF} \uparrow \text { after } 1 \mathrm{~m} \text { and } \\
12 \mathrm{~m} \text { in } \mathrm{CT}+\mathrm{vs} \\
\mathrm{T} 0\end{array}$} \\
\hline & & $23 / 23 F(59 \pm 9)$ & Breast 0-II & HTx & & \\
\hline Petr [140] & $3 \mathrm{~T}$ & $24 / ?(54 \pm 14)$ & GBM IV & $\begin{array}{l}\text { IMRTx } 60 \text { Gy, } \\
\text { TMZ } 75 \text { mg/m2 }\end{array}$ & pCASL & $\begin{array}{l}\mathrm{CBF} \downarrow 9.8 \% \text { in } \mathrm{GM} \\
\text { after } 3 \text { and } 6 \mathrm{~m} \\
\text { vs T0 }\end{array}$ \\
\hline
\end{tabular}


Table 3 (continued)

\begin{tabular}{|c|c|c|c|c|c|c|}
\hline Study & Modality/MRI field & $\begin{array}{l}\text { Number/female } \\
(\text { age } \pm \text { SD y) }\end{array}$ & $\begin{array}{l}\text { Tumor Type/WHO } \\
\text { grade }\end{array}$ & Treatment & Imaging & Main finding \\
\hline \multirow[t]{2}{*}{ Petr [9] } & \multirow[t]{2}{*}{$3 \mathrm{~T}$} & $44 / 20 \mathrm{~F}(55 \pm 13)$ & \multirow[t]{2}{*}{ GBM IV } & $\begin{array}{l}\text { RTx } 60 \text { Gy, TMZ } \\
75 \mathrm{mg} / \mathrm{m} 2\end{array}$ & \multirow[t]{2}{*}{ pCASL } & \multirow{2}{*}{$\begin{array}{l}\mathrm{CBF} \downarrow 10-11 \% \text { in } \\
\mathrm{GM} \text { after } 3 \text { and } \\
6 \mathrm{~m} \text {, proton and } \\
\text { photon therapy } \\
\text { comparable } \downarrow \text { vs T0 }\end{array}$} \\
\hline & & $16 / 5 \mathrm{~F}(52 \pm 16)$ & & $\begin{array}{l}\text { Proton } 60 \mathrm{~Gy} \text {, TMZ } \\
75 \mathrm{mg} / \mathrm{m} 2\end{array}$ & & \\
\hline \multirow[t]{2}{*}{ Wang [52] } & \multirow[t]{2}{*}{$3 \mathrm{~T}$} & $16 / ?(65 \pm 9)$ & LGG I-II & RTx 36-63 Gy & \multirow[t]{2}{*}{ pCASL } & $\begin{array}{c}\mathrm{CBF} \downarrow 7-18 \% \text { after } \\
2-4 \mathrm{~m} \text { vs T0 }\end{array}$ \\
\hline & & $19 / ?(62 \pm 9)$ & HGG III-IV & & & $\begin{array}{l}\mathrm{CBF} \uparrow 0-18 \% \text { after } \\
2-4 \mathrm{~m} \text { vs } \mathrm{T} 0\end{array}$ \\
\hline Weber [42] & $1.5 \mathrm{~T}$ & $25 / 11 F(25-73)$ & Metastases & SRS 16-20 Gy & PASL & $\begin{array}{c}\leftrightarrow \text { CBF WM/GM } \\
\text { until } 6 \text { m vs T0 }\end{array}$ \\
\hline Artzi [50] & $3 \mathrm{~T}$ & $\begin{array}{l}26 / 16(51 \pm 12) \\
11 / ?(37 \pm 11)\end{array}$ & $\begin{array}{l}\text { HGG III-IV } \\
\mathrm{HC}\end{array}$ & $\begin{array}{l}\text { RTx, BEV } \\
\text { No }\end{array}$ & DCE & $\begin{array}{l}\leftrightarrow \mathrm{V}_{\mathrm{p}} \text { in } \mathrm{WM} \text { or GM } \\
\quad \text { vs T0 }\end{array}$ \\
\hline Cao [47] & $1.5 \mathrm{~T}$ & $10 / 1 \mathrm{~F}(45 \pm 16)$ & CNS I-III & $\begin{array}{l}\text { 3D-CRTx } \\
\text { 50-60 Gy }\end{array}$ & DCE & $\begin{array}{c}\mathrm{V}_{\mathrm{p}} \uparrow 12 \% \text { after } 1 \mathrm{~m}, \\
\mathrm{~K}^{\text {trans }} \uparrow 52 \% \text { at w6 } \\
\text { of therapy vs T0 }\end{array}$ \\
\hline Fahlström [48] & $1.5 \mathrm{~T}$ & $12 / ? \mathrm{~F}(56 \pm 11)$ & HGG III-IV & $\begin{array}{l}\text { IMRTx } 60 \text { Gy, } \\
\text { TMZ } 75 \text { mg/m2, } \\
\text { BEV }\end{array}$ & DCE & $\begin{array}{l}\mathrm{V}_{\mathrm{e}} \uparrow 8 \% \text { after } 3 \mathrm{~m} \\
\text { vs T0 }\end{array}$ \\
\hline Farjam [49] & $1.5 \mathrm{~T}$ & $27 / 10 \mathrm{~F}(50 \pm 12)$ & CNS I-III & $\begin{array}{l}\text { IMRT/3DCRTx } \\
50-60 \mathrm{~Gy}\end{array}$ & DCE & $\begin{array}{l}\mathrm{K}^{\text {trans }} \uparrow \text { in hippocam- } \\
\text { pus after } 1 \mathrm{~m} \text { vs T0 }\end{array}$ \\
\hline Wong [51] & $3 \mathrm{~T}$ & $14 / 9 F(?)$ & Metastases & WBRTx 37.5 Gy & DCE & $\begin{array}{l}\leftrightarrow \text { after } 1-5 \text { months } \\
\text { vs T0 }\end{array}$ \\
\hline Gulaldi [33] & SPECT & $18 / 5 F(42 \pm 13)$ & Glioma II-IV & $\begin{array}{l}\text { RTx 54-64 Gy, } \\
\text { CTx }\end{array}$ & Tc-99 m-HMPAO & $\begin{array}{c}\mathrm{CBF} \downarrow 18.5 \% \\
\text { in }<3 \mathrm{~Gy}, 22.5 \% \\
\text { in }>3 \text { Gy after } \\
3-6 \mathrm{~m} \text { vs T0 }\end{array}$ \\
\hline Hahn [34] & PET & $11 / 5 \mathrm{~F}(48 \pm ?)$ & CNS I-III & 3DCRTx 50-60 Gy & ${ }^{15} \mathrm{O}-\mathrm{H}_{2} \mathrm{O}$ & $\begin{array}{l}\mathrm{CBF} \uparrow 0.6-5.1 \% \\
\text { in }>10 \mathrm{~Gy} \text { at } 3 \mathrm{w} \\
\text { vs }<5 \mathrm{~Gy}, \mathrm{~T} 0 ; \\
\text { resolved after } 6 \mathrm{~m} \\
\text { vs T0 }\end{array}$ \\
\hline Taki [32] & SPECT & $13 / 8 \mathrm{~F}(52 \pm ?)$ & $\begin{array}{l}\text { CNS, AVM, metas- } \\
\text { tases }\end{array}$ & SRS 14-25 Gy & Tc-99 m-HMPAO & $\begin{array}{l}\mathrm{CBF} \downarrow 4,7 \% \text { whole } \\
\text { brain after } 2 \mathrm{w} \text { and } \\
3 \mathrm{~m} \text { in } 2-5 \mathrm{~Gy} \text { vs } \\
\text { T0 }\end{array}$ \\
\hline Vera [35] & SPECT & $12 / 5 \mathrm{~F}(11 \pm ?)$ & AML, AAL & $\begin{array}{l}\text { WBRTx } 12-18 \mathrm{~Gy} \text {, } \\
\text { HD ara-C } \\
18-36 \mathrm{~g} / \mathrm{m} 2\end{array}$ & Tc-99 m-HMPAO & $\begin{array}{l}\text { Heterogeneous CBF } \\
\text { in cortex, cerebel- } \\
\text { lum after } 1 \mathrm{~m} \text { vs T0 }\end{array}$ \\
\hline
\end{tabular}

Tumor type: $A A L$ acute lymphoid leukemia, $A M L$ acute myeloid leukemia, $A V M$ arteriovenous malformation, $C N S$ central nervous system, $G B M$ glioblastoma, $H C$ healthy control, $H G G$ high-grade glioma, $L G G$ low-grade glioma, $M B$ medulloblastoma, $P A$ pilocytic astrocytoma, recGBM recurrent GBM, WHO World Health Organization

Treatment type: $B E V$ bevacizumab, $C T x$ chemotherapy, $C P T$ cisplatin, $C R T x$ conformal RTx, $C P$ cyclophosphamide, $D X M$ dexamethasone, $D T X$ docetaxel, DXR doxorubicin, HTx hormone therapy, IMRTx intensity-modulated RTx, RTx radiotherapy, SRS stereotactic radiosurgery, $T M Z$ temozolomide, WBRTx whole-brain RTx

Imaging: $A S L$ arterial spin labeling, $D S C$ dynamic susceptibility contrast, $D C E$ dynamic contrast enhanced, $p C A S L$ pseudo-continuous ASL, $P A S L$ pulsed ASL

Findings: $C B F$ cerebral blood flow, $C B V$ cerebral blood volume, $K^{\text {trans }}$ exchange rate between $\mathrm{V}_{\mathrm{e}}$ and $\mathrm{V}_{\mathrm{p}}, V_{e}$ extravascular, extracellular fractional volume, $G M$ gray matter, $V_{p}$ intravascular blood plasma fractional volume, $M C A$ middle cerebral artery, $T 0$ pre-therapy baseline, $W M$ white matter

and by $18.5 \%$ (relative CBF normalized to the contralateral region, $<3$ Gy at $0.5-6$ months after RTx [33]). After high-dose radiation, contradicting results were reported in relative CBF: $22.5 \%$ decrease ( $>3 \mathrm{~Gy}$, normalization to the contralateral region [33]) and 0.6-5.1\% increase (> $10 \mathrm{~Gy}$, normalized to < $5 \mathrm{~Gy}, 3$ weeks after 3D-CRTx) [34]. Qualitatively evaluated regions with hypoperfusion in cortex and cerebellum were reported in acute myeloid 
and lymphoid leukemia (AML and ALL) patients after CTx, and whole-brain RTx (WBRTx) or total-body RTx [35].

\section{Dynamic susceptibility contrast (DSC)}

Default DSC assessment provides relative CBF and CBV values only. These estimates can be either semi-quantitative absolute values using normalization to individual integrated arterial input function (AIF), or normalized to a reference region. Using AIF-based quantification in braintumor patients, a 30\% decrease in CBV was documented 6 months after WBRTx [36], and after fractionated RTx [37], and with reductions of $16-21 \%$ in both CBV and CBF at 3 months post-therapy [38]. Up to $40 \%$ CBV reduction in the corpus callosum was observed one year after therapy, however, the exact CBV normalization was not mentioned and the regional values were highly variable across time points and brain regions [39]. One of the few contradictory findings showed a large CBV $(42.2 \%)$ and CBF (33.9\%) increase at 1 month after SRS, but only in regions receiving between 5 and 10 Gy [40].

A series of studies used normalization to regions receiving low doses of radiation in brain tumor patients. Normalization to regions $<15$ Gy and $<0.5$ Gy yielded only non-significant changes 2 months after RTx [41] and 3 months after SRS [42]. Fahlström et al. normalized to a $0-5$ Gy region in $\mathrm{WM}$, and reported a CBV decrease of 4.6-6.7\% in GM, and CBF decreases of 5.1-12.5\% in GM and $3.1-7.4 \%$ in WM. Interestingly, changes were not significant when normalizing to a GM region [43]. Transient reductions of $5 \%$ in microvascular $\mathrm{CBV}$ and $\mathrm{CBF}$ were observed in low-dose regions at 6-9 months normalized to $<1$ Gy region. A corresponding 5\% increase in the average vessel caliber was observed when using a combined gradient-echo spin-echo based readout scheme [44].

Some of the studies above looked at mean regional imaging values at regions defined by their dose from the dose-distribution maps and reported non-significant RTdose dependence [37, 38, 41], whereas an inverse correlation of CBV and CBF to dose in WM was observed only by Fahlström et al. [43]. While some studies report that CBV plateaus several months after brain RTx and does not resolve for years [37], resolution of perfusion changes in the period of 9-18 months after therapy was also observed, though without adjusting for subgroups at baseline [44].

Mixed results were reported in NABT following antiangiogenic treatment in glioblastoma patients varying from no perfusion change [45] to a $20-30 \%$ CBV decrease 3-7 months after therapy onset compared to both baseline and to bevacizumab-naive patients [46].

\section{Dynamic contrast enhanced (DCE)}

DCE primarily measures the intravascular blood plasma fractional volume $\left(\mathrm{V}_{\mathrm{p}}\right)$, the extravascular, extracellular fractional volume $\left(\mathrm{V}_{\mathrm{e}}\right)$, and exchange rate, i.e. BBB leakage, between these two compartments $\left(\mathrm{K}^{\text {trans }}\right)$. The reviewed studies reported DCE changes solely in patients with primary brain tumors or metastases receiving cranial radiation.

$A V_{p}$ increase of 4-10\% was observed at therapy week 3 of RTx, peaking at $12 \% 1$ month after therapy, resolving to 3 -week values at 6 months. $\mathrm{K}^{\text {trans }}$ increase of $39-52 \%$ at week 6 of therapy resolved to pre-therapy values at 6 months, showing correlation to the regional dose and overall irradiated volume [47]. No other DCE studies gave clear results. Transient $\mathrm{V}_{\mathrm{e}}$ increase by $8 \%$ was observed in GM 3 months post-RTx, but $\mathrm{K}^{\text {trans }}$ and $\mathrm{V}_{\mathrm{e}}$ at other times had similar magnitudes but were not significant [48]. A longitudinal $\mathrm{K}^{\text {trans }}$ increase in the hippocampus was claimed one month after RTx, without providing details of the effect size [49]. No changes in $V_{p}$ were observed after RCTx [50], nor in the non-normalized area under the curve (AUC) 6 months after WBRTx [51].

\section{Arterial spin labeling (ASL)}

ASL did not show CBF changes in NABT at 3 months after SRS in brain metastases patients [42], and unclear findings of both increase and decrease were reported in patients diagnosed with high-grade (HGG) and low-grade gliomas (LGG), respectively [52]. A larger prospective study in glioblastoma patients was, however, in line with the majority of DSC results showing 10-11\% CBF decrease 3 and 6 months after photon RCTx at both low and high-dose regions, with a comparable decrease seen in proton-therapy patients alone [9]. CBF decrease was shown in pediatric patients with posterior fossa tumors 7 years after RCTx. CBF in patients with medulloblastoma undergoing RCTx was both lower than in controls and in RCTx-free patients with astrocytoma [53]. Bevacizumab-related acute CBF decrease of $13 \%$ was also shown with ASL in glioblastoma patients [54]. In metastasis-free breast cancer patients 1 month after CTx, a CBF increase of $7-12 \%$ was shown with respect to both baseline and healthy controls, despite the anti-angiogenic effects of CTx [55], and a similar increase was confirmed by another group compared with both the CTx-naive patients and healthy controls $[56,57]$.

\section{Perfusion imaging discussion}

Perfusion decrease after brain RTx was demonstrated by most quantitative perfusion studies, although absolute perfusion values were not always obtained. Using PET (and, to some extent, SPECT) absolute values can only be provided 
when a properly calibrated acquisition and processing is performed. And DSC and DCE can provide semi-quantitative values only. Therefore, most of the included studies normalized the acquired perfusion results to whole-brain values, a reference anatomical region, or to a low-dose region assuming to be relatively unaffected by the therapy. However, either of these assumptions might be invalid as effects of therapy were shown across the entire brain and in the low-dose regions as well. Such normalization might then mask overall perfusion changes. None of the reviewed studies were able to distinguish between the separate effects of CTx and RTx, although both were independently shown to affect perfusion. Most studies investigated acute or early delayed changes in perfusion and did not investigate latedelayed effects. While a few studies suggested that perfusion changes might resolve after several months, these have to be interpreted with care as the group sizes typically decrease at later time points, and no larger studies with observing longitudinal perfusion deficits after 1 year exist.

Technique repeatability is an important aspect needed for assessing and comparing the significance of the findings between studies. We provide here the literature values of repeatability of techniques in normal tissue for all techniques with at least two reviewed references and a single positive imaging finding. ${ }^{99 \mathrm{~m}} \mathrm{Tc}-\mathrm{HMPAO}$ SPECT repeatability of absolute flow on rescan was $15.0 \pm 1.5 \%$ [58]. Very good repeatability of $\mathrm{CBV}, \mathrm{K}^{\text {trans }}$, and $\mathrm{CBF}$, respectively, was reported for DSC (3-11\%) [59], DCE (7.7\%) [60] and ASL (6.6-14.8\%) [30]. These, however, greatly depend on the used parameters, sequence implementation, or models used for quantification and can vary substantially between studies [61, 62].

\section{Metabolic imaging}

Magnetic resonance spectroscopy (MRS) enables the detection of MR signals generated by chemical compounds other than water, such as $\mathrm{N}$-acetyl aspartate (NAA), creatine $(\mathrm{Cr})$, choline (Cho), glutamate, myo-inositol (mI), lactate, and $\gamma$-aminobutyric acid. MRS provides an MR spectrum, originating from the nuclei in atoms (e.g. $\left.{ }^{1} \mathrm{H}\right)$, graphically displaying measured signal intensity as a function of their resonance frequency. The relative area under each peak is directly proportional to the tissue concentration of the corresponding nuclei [63]. MRS allows assessing the in-situ tissue biochemistry, which may relate to tumor characteristics from different brain-tumor types. The typical excitation and localization scheme is PRESS (point resolved spectroscopy). Increased choline and decreased NAA levels are typically seen in tumors, whereas decreased NAA in NABT indicates decreased neuronal density. Additionally, ${ }^{1} \mathrm{H}-\mathrm{MRS}$ is highly sensitive to metabolic abnormalities underlying cognitive deficits [64]. Besides MRS, PET is the most used modality to measure brain metabolism. Fluorodeoxyglucose (FDG), $18 \mathrm{kDa}$ translocator protein (TSPO), and tropen derivative (TRODAT) based tracers can be used, respectively, to measure brain glucose uptake, microglia and astrocyte activation, and the presence of dopamine active transporter. CTx is suspected to elevate inflammatory cytokine levels [65], possibly detected by FDG-PET, decrease dopamine release [66], measurable by TRODAT-SPECT, or directly by TSPOPET through microglia and astrocyte [67], all mechanisms possibly contributing to cognitive decline.

This review contains 39 studies on metabolic imaging: MRS $(n=23)$, FDG-PET $(n=6)$, DOPA-PET $(n=1)$, TSPOPET $(n=1)$, and TRODAT-SPECT $(n=1)$. Results are summarized in Table 4 and the modified QUADAS- 2 scores are presented in Supplementary Table 2.

\section{Magnetic resonance spectroscopy (MRS)}

Only two studies did not find significant changes in NAA, choline, or creatinine, or their ratios in NABT following cranial RTx - in brain metastasis patients after 1 to 12 months [68], and in CNS and leukemia patients after 10 and 8 years [69]. Almost all others reported a decrease in NAA, Cr, or $\mathrm{NAA} / \mathrm{Cr}$, or an increase in Cho or $\mathrm{Cho} / \mathrm{Cr}$. While one of the first cross-sectional studies on ${ }^{1} \mathrm{H}$-MRS changes in NABT in ALL subjects showed changes only at dose $>59$ Gy [70], later studies in gliomas patients found changes even in doses below $6 \mathrm{~Gy}$, compared with healthy controls and pre-therapy baseline [71], or as early as 1 week after WBRTx [72]. Limited evidence of dose effect was available comparing low and high-dose regions after RCTx [73], and patients with and without RTx [74]. Combined RCTx seemed to worsen the effect in pediatric brain tumor patients in comparison with RTx only [75]. While these studies mainly focused on regions contralateral to the tumor, metabolic changes were also reported in specific anatomical regions irrespective of tumor location. Hippocampal metabolic changes were reported 1 month [76] and 4 months after WBRTx [77, 78]. Additionally, a progressive worsening was reported between week 4 of 3D-CRTx until 6 months after, with $\mathrm{NAA} / \mathrm{Cr}$ in the corpus callosum further decreased from 10 to up to $18 \%$ [79]. However, the decrease of NAA/Cho by $19 \% 4$ months after RTx resolved to pre-therapeutic levels another 4 months later in another study [80]. Only two studies were in partial conflict with the results above. A decrease of both NAA/Cr and Cho/Cr in NABT was reported until 6 months after 3D-CRTx [81]. A lower $\mathrm{Cho/Cr}$, and higher $\mathrm{NAA} / \mathrm{Cr}$ and NAA/Cho in normal-appearing WM (NAWM) after RTx was reported with respect to healthy controls [82].

Besides a single pediatric study with ALL patients, reporting decreased choline levels [83], metabolic changes following CTx treatment of non-CNS tumors were mostly consistent with brain RT-related changes. ALL patients 


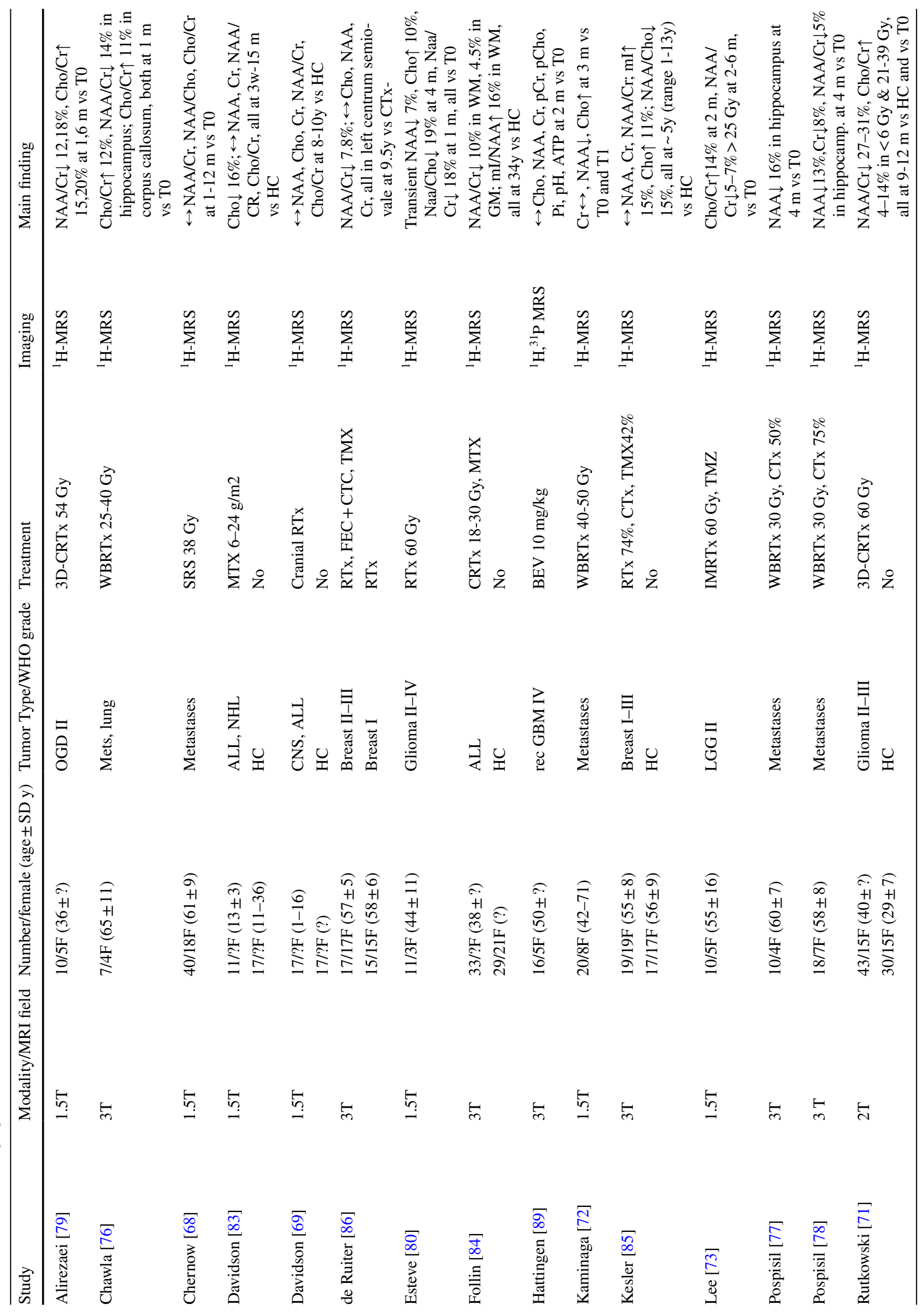




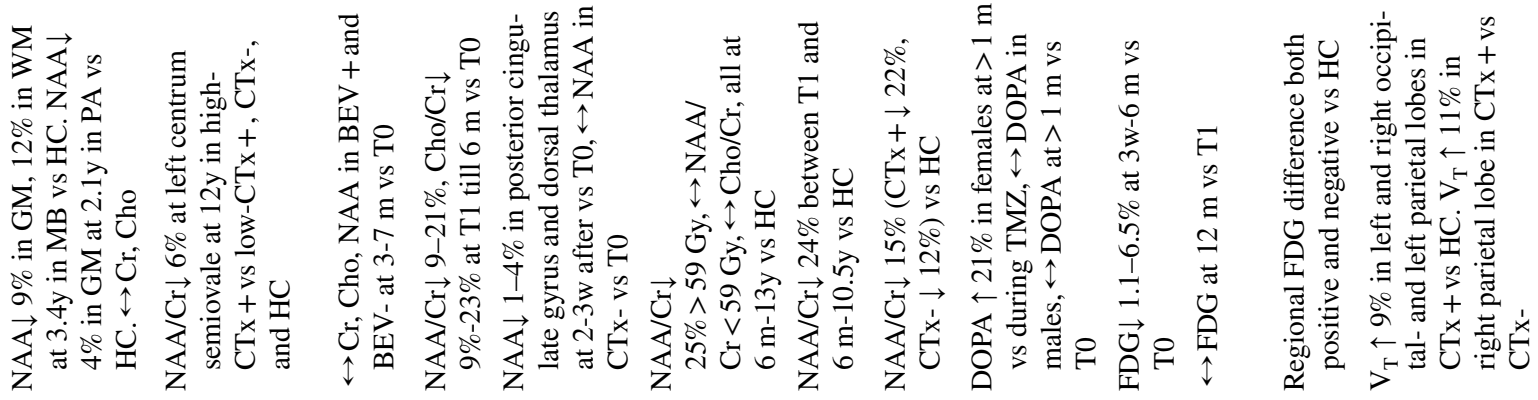

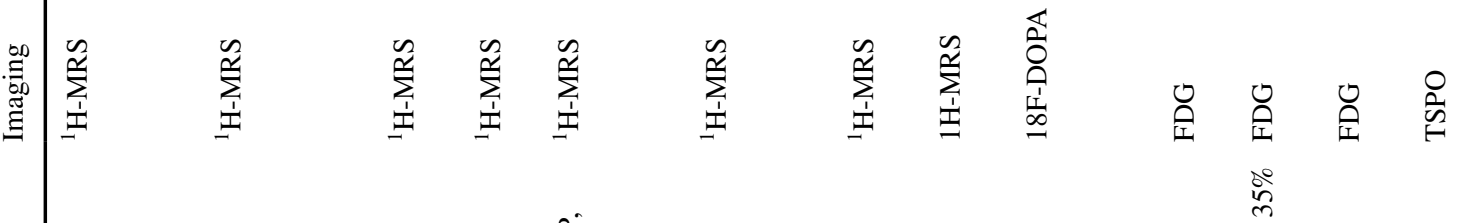

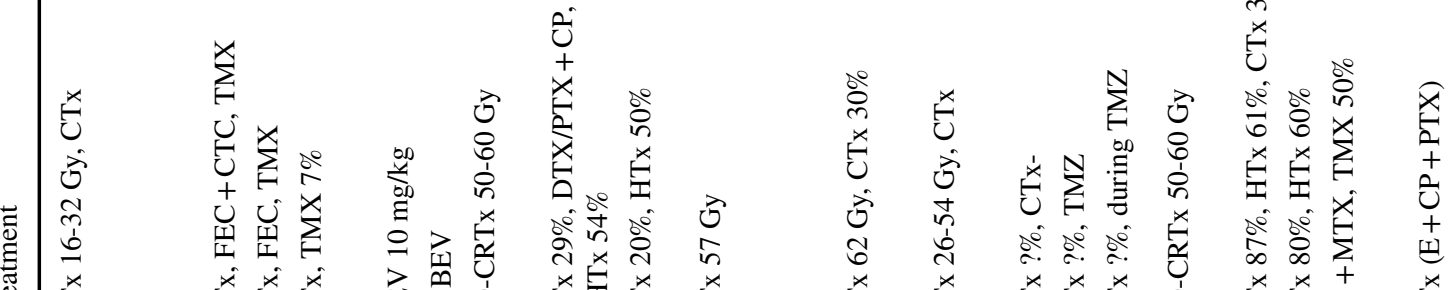

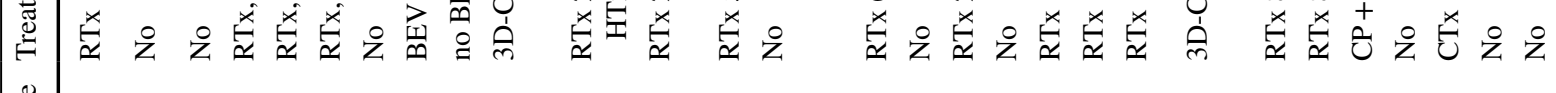

$\lessdot \quad$

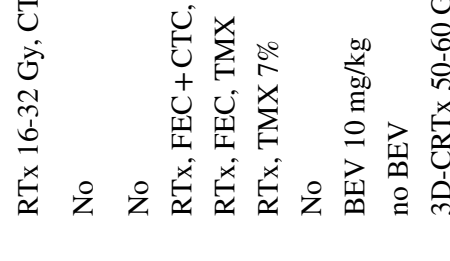

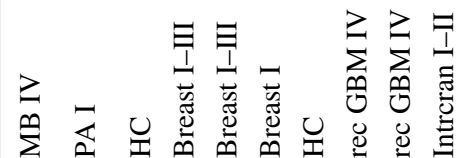

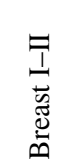

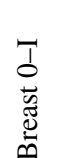

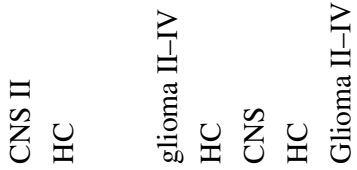

章

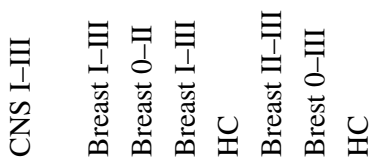

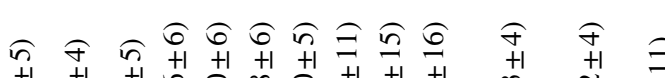

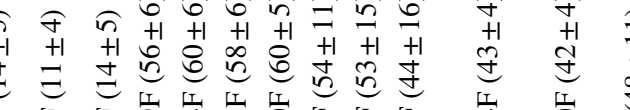

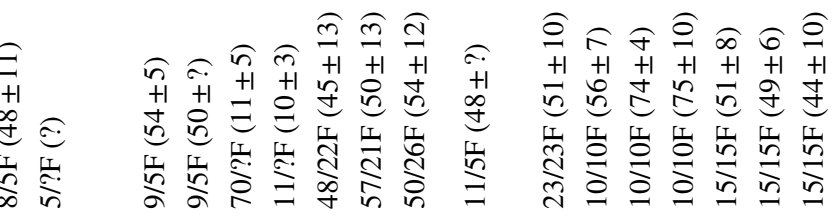

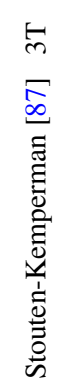

泉 突

$\stackrel{5}{n}$ 辛

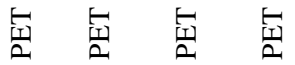

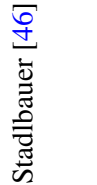

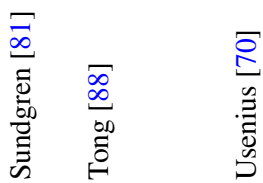

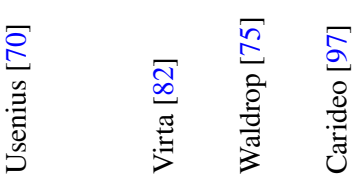

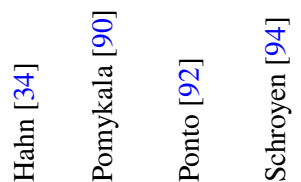




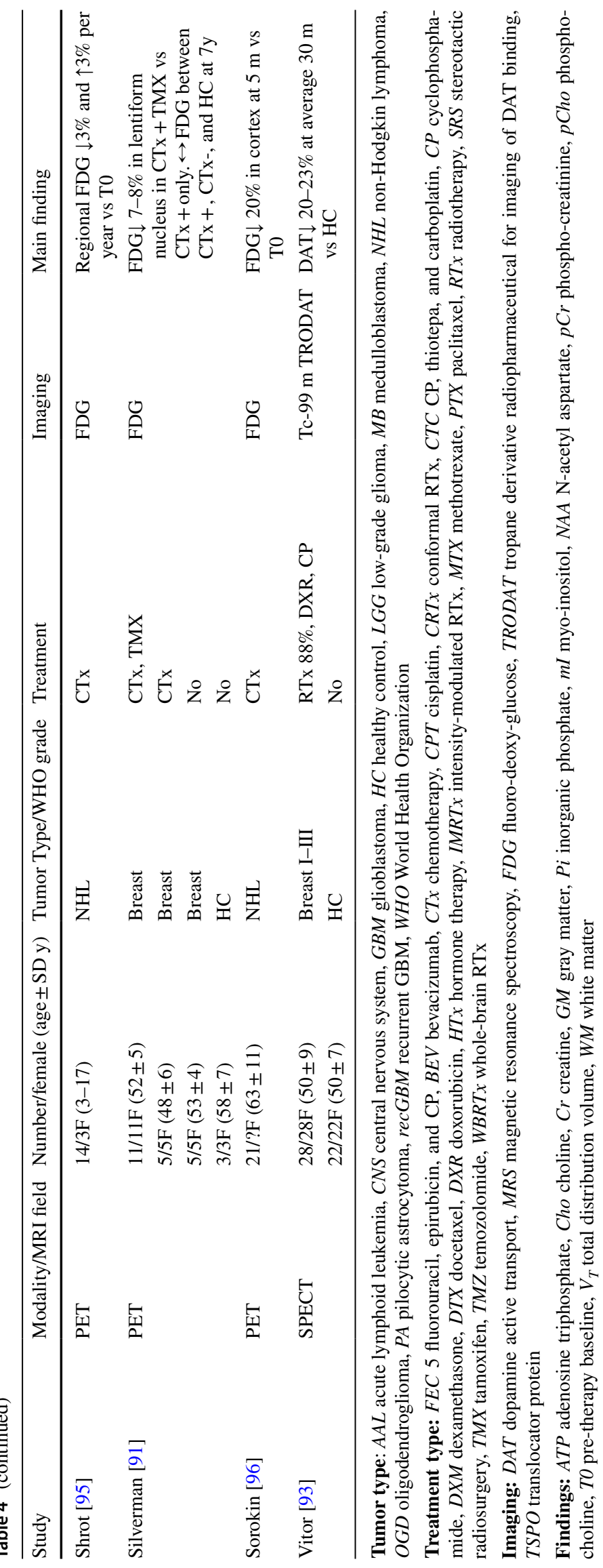


receiving methotrexate and cranial RTx at 34 years after the diagnosis showed a decrease of NAA/Cr and an increase of myo-inositol (mI) in deep WM and parieto-occipital GM [84]. Metabolic changes were also shown cross-sectionally in four studies including breast cancer patients undergoing locoregional chest RCTx and hormone therapy. Higher mI and choline, and lower NAA/Cho were reported 5 years after therapy compared with healthy controls [85]. But NAA/Cr decrease was shown also after 10 years in comparison with CTx-naïve patients treated with RTx only [86], or after 12 years in comparison with healthy controls or patients without chemo- or hormone-therapy [87]. Lastly, NAA and $\mathrm{Cr}$ decrease in the posterior cingulate gyrus and dorsal thalamus at 2-3 weeks after therapy was shown compared with baseline in patients with RCTx but not in patients with hormone therapy only [88].

Finally, the influence of anti-angiogenic therapy on NABT was studied longitudinally in recurrent glioblastoma in two studies after 3 and 7 months [46] and after 2 months [89]. Neither study found significant changes in either NAA, $\mathrm{Cr}$, or Cho, and the second study also reported a lack of changes in ${ }^{31} \mathrm{P}$ results of $\mathrm{pH}$, adenosine triphosphate, phosphomonoesters, phosphodiesters, phosphocreatine, and inorganic phosphate.

\section{PET and SPECT metabolic imaging}

Similar to the perfusion findings, the metabolic measurements were mostly normalized to whole brain or low-dose region values. Consistent with other findings after brain RTx, glucose uptake decreased 3 weeks and 6 months posttreatment in the region $>10$ Gy when normalized to $<5$ Gy region [34]. No clear findings were obtained with FDG-PET in three studies with breast cancer patients. No uptake differences between baseline and $1 \mathrm{y}$ after chemo and hormone therapy were observed when normalizing to the global mean [90]. No differences were observed between CTx and control groups 7 years after the therapy, although a 7-8\% decrease was observed in the lentiform nucleus between the hormone and CTx and hormone-therapy only groups when normalized to the all-ROIs mean [91]. Higher uptake than in controls was observed 16 years after chemo and hormone therapy in postcentral gyrus and corpus callosum after a global normalization, but the effect was opposite in frontal gyri, substantia nigra, and brainstem [92]. Breast cancer survivors reporting chemo-fog were examined using ${ }^{99} \mathrm{Tc}-$ TRODAT-1 SPECT measuring dopamine transport, reporting a $20-23 \%$ decrease in the putamen, caudate, and striatum [93], and TSPO-PET showed signs of neuroinflammation in the occipital and parietal lobes both compared to nontreated patients and a healthy group 4 weeks after $(6$ months of) CTx [94]. Finally, two studies reported on CTx effects in patients with non-Hodgkin lymphoma. A glucose uptake increase was measured in the parietal and cingulate cortex, and a decrease in basal ganglia, brainstem, and thalamus when normalized to whole-brain activity [95]. In one of the two studies that used non-normalized standard uptake values (SUV), mean cortical glucose uptake decreased 20\% between pre-therapy and 1 to 14 months post-therapy [96]. The other study reported a brief $21 \%$ increase of ${ }^{18} \mathrm{~F}$-DOPA SUV during TMZ therapy in female glioma patients [97].

\section{Metabolic imaging discussion}

Absolute quantification of ${ }^{1} \mathrm{H}$-MRS signals requires normalization to the concentration of an internal or external reference metabolite, of which stability is of utmost importance. In the reviewed studies, typically an internal reference was used, either the tissue-water concentration or an individual metabolite (e.g. creatinine). Notably, several studies reported creatinine changes in NABT after cancer treatment, which may confound metabolic ratios. Moreover, despite that most studies with non-CNS tumors placed the MRS ROI at an anatomical location in deep WM, the majority of studies with CNS tumors specified the location as contralateral to the tumor, without providing the detailed anatomical location of the tumor, the distance from the tumor, or WM and GM content. This may have led to signal contamination with tumor-related changes, and the mixing of signals from different tissue types. Consistent voxel prescription and anatomical landmarks are recommended to improve inter-patient and inter-study reproducibility and to comply with the recent consensus on MRS reporting standards [98]. Additionally, a further consensus recommends the sLASER sequence for 3T MRI [99], while PRESS was used in the majority of the reviewed studies. Another main shortcoming was that hormone therapy with tamoxifen is known to influence brain metabolites [100] and most studies reviewed here were not designed to easily disentangle the effect of different chemotherapeutics and tamoxifen. Finally, more attention should be given to other metabolites than NAA, choline, and creatinine since changes related to cognitive performance were reported in other metabolites, e.g., mI.

Reproducibility of MRS at $3 \mathrm{~T}$ with PRESS sequence showed a median between-session coefficient of variation for the five major metabolites - NAA, $\mathrm{tCr}$, Glu, tCho, and Ins-between 2.5 and 5.3\% [101], and similar values below $5 \%$ were obtained at $7 \mathrm{~T}$ with semi-LASER sequence [102]. In oncological patients, the test-retest coefficient of variation in ${ }^{18}$ F-FDG PET was estimated to be $10.0 \pm 3.1 \%$ for tumor SUV mean [103] and can be expected to be lower in normal brain tissue, although no clinical studies are available to confirm this assumption.

The main concern for PET/SPECT was that its results were normalized to the whole brain or a region receiving a low dose of radiation. For treatments that are likely to affect 
the entire brain-e.g., chemo- or hormone therapy-this may have masked true metabolic changes. The use of SUV might be a better solution for future studies if additional care is taken to alleviate the shortcomings of SUV [104].

\section{Advanced diffusion, susceptibility, and relaxation imaging}

Diffusion-weighted imaging (DWI) and diffusion tensor imaging (DTI) models are most commonly used for diffusion imaging of WM in the clinical context. While sensitive to changes in the tissue microstructure, specificity to individual microstructural features appears to be insufficient. Two other models-neurite orientation dispersion and density imaging (NODDI) [105] and diffusion kurtosis imaging (DKI) [106] —are tackling this drawback by analyzing multi-shell diffusion data with b-values above $1500 \mathrm{~s} /$ $\mathrm{mm}^{2}$ [107]. NODDI attempts to disentangle the microstructural complexity of nerve fibers in vivo by delivering multi-compartmental maps of neurite orientation dispersion index (ODI) and neurite density index (NDI). DKI delivers a unitless apparent kurtosis factor $\mathrm{K}$ describing the share of non-Gaussian water movement. A clinical application for NODDI in oncological brain MRI is the quantification of white matter structural loss due to treatment, as neural density is expected to decrease due to brain radiation. DKI reveals tissue inhomogeneities, which can be used to evaluate tumor and NABT response to treatment through its presumed sensitivity to cell density and heterogeneity [108], such as in inflammation or apoptosis. However, within the limited scanning time, it is important to consider what features are of interest as multi-shell sequences (e.g. NODDI) typically have longer scanning times.

Quantitative susceptibility mapping (QSM) and myelin water imaging (MWI) are two techniques based on the quantification of T2* relaxation. QSM modifies susceptibility-weighted imaging (SWI) to detect weak susceptibility changes and generates maps of quantified susceptibility parameters, for example, based on multi-echo acquisitions [109]. QSM, or directly T2* mapping, can be used to quantitatively assess (micro)hemorrhages and iron deposition from blood, as an association between microbleed incidence with RTx dose and cognitive decline was previously shown on the qualitative evaluation of SWI [12]. MWI is based on deconvolution of myelin-water components of T2-decay curves $[110,111]$, and is ideal for imaging de- and remyelination as well as gliosis. While atrophy after cancer therapy can be identified in T1-weighted images, T1-time mapping can possibly identify more subtle changes in tissue density, gliosis, or edema. Finally, quantitative magnetization transfer (qMT) is a technique that can be used to estimate the amount of magnetization transfer between the semi-solid macromolecular pool—including myelin—and the free water pool but needs additional multi-frequency acquisition to generate the MT spectrum [112].

This review contains 12 studies on advanced diffusion, susceptibility, and relaxation imaging: NODDI $(n=3)$, DKI $(n=7)$, qMT $(n=1)$, QSM $(n=2)$, MWI $(n=1)$, and relaxometry $(n=2)$. Results are summarized in Table 5 and the modified QUADAS-2 scores are in Supplementary Table 3.

\section{Advanced diffusion imaging}

Limited evidence on cancer-therapy-related changes in NABT measured by advanced diffusion models appears to be available. While a baseline correlation of NDI with tumor volume was shown [113], no significant difference in mean kurtosis was reported in WM contralateral to the tumor both in glioblastoma patients [114] and breast cancer patients [115]. The latter study also showed no changes in myelin water fraction, or ODI, NDI, or isotropic volume (Viso) derived from NODDI [115]. However, 11-12\% decreases in mean kurtosis in the temporal lobe were measured in GM and WM in patients with nasopharyngeal carcinoma 1 week after RCTx with a further decrease to $34-39 \%$ after 1 year [116], and a decrease in WM, but not in GM was also found 1.2-12.2y after pediatric germ cell tumor [117]. An increase of radial kurtosis by $9 \%$ in NAWM was reported in testicular cancer survivors after CTx [118]. Last, an elevated Viso in central WM and higher NDI in the corticospinal tract was found in survivors of pediatric sarcoma at 2 to 20 years after CTx [119].

\section{Quantitative susceptibility and relaxation mapping}

No QSM changes were observed in breast cancer patients at 1 and 5 months after CTx in comparison with a CTx-group [120] nor longitudinally in glioblastoma patients [121]. No longitudinal changes were detected in NAWM of glioblastoma patients using qMT or T2* mapping [122]. Finally, a $4.5 \%$ decrease of T1-time was detected both in GM and WM of pediatric brain tumor patients after fractionated RTx at an average of $0.8 \mathrm{y}$ follow-up [123].

\section{Advanced diffusion, susceptibility, and relaxation imaging discussion}

The level of evidence for therapy-related changes in NABT as identified by advanced diffusion techniques (NODDI, DKI) techniques was low as the findings were often non-significant or inconsistent. A potential explanation is that study sample sizes were small and the study designs were mostly cross-sectional. This was similarly true for QSM, qMT, MWI, and T1 and T2* mapping studies. More specifically, only a single T1-mapping study identified treatment-related effects in NABT. Nevertheless, first encouraging results do 
Table 5 Advanced diffusion, susceptibility, and relaxation imaging results

\begin{tabular}{|c|c|c|c|c|c|c|}
\hline Study & $\begin{array}{l}\text { Modality/ } \\
\text { MRI field }\end{array}$ & $\begin{array}{l}\text { Number/female } \\
(\text { age } \pm \text { SD y) }\end{array}$ & $\begin{array}{l}\text { Tumor } \\
\text { Type/WHO } \\
\text { grade }\end{array}$ & Treatment & Imaging & Main finding \\
\hline Chen [120] & $3 \mathrm{~T}$ & $\begin{array}{l}14 / 14 \mathrm{~F}(66 \pm 5) \\
13 / 13 \mathrm{~F}(68 \pm 6)\end{array}$ & $\begin{array}{l}\text { Breast I-III } \\
\text { HC }\end{array}$ & $\begin{array}{l}\text { CTx } \\
\text { No }\end{array}$ & QSM & $\begin{array}{l}\leftrightarrow \text { QSM in caudate, } \\
\text { globus pallidus, puta- } \\
\text { men, thalamus at } 1 \mathrm{~m}, \\
5 \mathrm{~m} \text { vs HC }\end{array}$ \\
\hline Cushing [121] & $3 \mathrm{~T}$ & 20/?F (?) & GBM IV & $\begin{array}{l}\text { RTx } 60 \text { Gy, TMZ, } \\
\text { ASCH }\end{array}$ & QSM & $\begin{array}{l}\leftrightarrow \mathrm{QSM} \text { in } \\
\mathrm{ASCH}+\text { and ASCH- } \\
\text { group at T1 vs T0 }\end{array}$ \\
\hline Mehrabian [122] & $3 \mathrm{~T}$ & $16 / 3 F(55 \pm ?)$ & GBM IV & RTx 60 Gy, TMZ & qMT & $\begin{array}{l}\leftrightarrow \mathrm{qMT} \text { in NAWM at } \\
3-8 \mathrm{~m} \text { vs T0 }\end{array}$ \\
\hline Cushing [121] & $3 \mathrm{~T}$ & 20/?F (?) & GBM IV & $\begin{array}{l}\text { RTx } 60 \text { Gy, TMZ, } \\
\text { ASCH }\end{array}$ & $\mathrm{T} 2 *$ & $\begin{array}{l}\leftrightarrow \mathrm{T} 2 * \text { in } \mathrm{ASCH}+\text { and } \\
\text { ASCH- group at T1 } \\
\text { vs T0 }\end{array}$ \\
\hline Steen [123] & $1.5 \mathrm{~T}$ & 21/?F (10 $\pm ?)$ & CNS I-IV & 3D-CRTx 56 Gy, CTx & $\mathrm{T} 1$ & $\begin{array}{l}\mathrm{T} 1 \downarrow 4.5 \% \text { in } \mathrm{GM} \text { and } \\
\mathrm{WM} \text { at } 0.8 \mathrm{y} \text { vs T0 }\end{array}$ \\
\hline \multirow[t]{3}{*}{ Billiet [115] } & \multirow[t]{3}{*}{$3 \mathrm{~T}$} & $25 / 25 \mathrm{~F}(44 \pm 6)$ & Breast I-III & $\begin{array}{l}\text { RTx } 92 \%, \text { TMX 60\%, } \\
\text { FEC }\end{array}$ & \multirow[t]{3}{*}{ MWI, DKI, NODDI } & \multirow[t]{3}{*}{$\begin{array}{l}\leftrightarrow \text { MK, ODI, NDI, } \\
\text { Viso, MWF at 3-4y }\end{array}$} \\
\hline & & $14 / 14 \mathrm{~F}(43 \pm 6)$ & Breast I-II & RTx 79\%, TMX 79\% & & \\
\hline & & $15 / 15 \mathrm{~F}(42 \pm 5)$ & $\mathrm{HC}$ & No & & \\
\hline Chakhoyan [114] & $3 \mathrm{~T}$ & $23 / ? F(57 \pm ?)$ & GBM IV & RTx 60 Gy, TMZ & DKI & $\begin{array}{l}\leftrightarrow \text { MK in NAWM } \\
\text { contralateral to the } \\
\text { tumor vs T0 }\end{array}$ \\
\hline Romero-Garcia [113] & $3 \mathrm{~T}$ & $17 / 8 \mathrm{~F}(36 \pm 10)$ & Glioma I-IV & RCTx $71 \%$ & NODDI & $\begin{array}{l}\text { Pre-operative NDI cor- } \\
\text { related with recovered } \\
\text { memory, recovery in } \\
\text { NDI correlated with } \\
\text { memory scores }\end{array}$ \\
\hline Sleurs [119] & $3 \mathrm{~T}$ & $\begin{array}{l}33 / ? \mathrm{~F}(23 \pm 4) \\
34 / ? \mathrm{~F}(22 \pm 4)\end{array}$ & $\begin{array}{l}\text { non-CNS } \\
\mathrm{HC}\end{array}$ & $\begin{array}{l}\text { CTx } \\
\text { No }\end{array}$ & NODDI, DKI & $\begin{array}{l}\text { Viso } \uparrow \text { in central WM, } \\
\text { NDI } \uparrow \text { in corticospinal } \\
\text { tract vs HC at } 9 \mathrm{y}\end{array}$ \\
\hline $\begin{array}{l}\text { Stouten-Kemperman } \\
\text { [118] }\end{array}$ & $3 \mathrm{~T}$ & $\begin{array}{l}27 / 0 \mathrm{~F}(43 \pm 8) \\
18 / 0 \mathrm{~F}(48 \pm 10)\end{array}$ & $\begin{array}{l}\text { Testicules } \\
\mathrm{HC}\end{array}$ & $\begin{array}{l}\text { BEP } \\
\text { No }\end{array}$ & DKI & $\begin{array}{l}\text { Radial kurtosis } \uparrow 9 \% \text { vs } \\
\text { CTx- }\end{array}$ \\
\hline Tso [117] & $3 \mathrm{~T}$ & $20 / 5 F(14 \pm 3)$ & GCT & $\begin{array}{l}\text { RCTx (30-54 Gy), } \\
\text { Surgery }(30 \%)\end{array}$ & DKI & $\begin{array}{l}\mathrm{MK} \downarrow \text { in } \mathrm{WM}, \leftrightarrow \text { in } \\
\mathrm{GM} \text {, at } 6.5 \mathrm{y} \text { (range } \\
1.2-12.2 \mathrm{y} \text { ) }\end{array}$ \\
\hline Wu [116] & $3 \mathrm{~T}$ & $56 / 22 \mathrm{~F}(47 \pm 11)$ & NPC II-IV & $\begin{array}{l}\text { IMRTx 68-72 Gy, } \\
\text { CPT, DTX }\end{array}$ & DKI & $\begin{array}{c}\text { MK } \downarrow 11 \%, 34 \% \text { in WM; } \\
12 \%, 39 \% \text { in GM at } \\
1 \mathrm{w}, 12 \mathrm{~m} \text { vs T0 }\end{array}$ \\
\hline $\mathrm{Wu}[126]$ & $3 \mathrm{~T}$ & $54 / 15 \mathrm{~F}(49 \pm 13)$ & NPC II-IV & $\begin{array}{l}\text { IMRTx 68-72 Gy, } \\
\text { CPT, DTX }\end{array}$ & DKI & $\begin{array}{l}\text { Axial, radial } \mathrm{MK} \downarrow \text { at } \\
1 \mathrm{~m} \text { in cogn-decline } \\
\text { vs non-decline at } 2 \mathrm{y}\end{array}$ \\
\hline
\end{tabular}

Tumor type: $C N S$ central nervous system, GBM glioblastoma, GCT germ cell tumor, $H C$ healthy control, NPC nasopharyngeal carcinoma, WHO World Health Organization

Treatment type: FEC 5 fluorouracil, epirubicin, and CP, ASCH ascorbate, BEP bleomycin, etoposide, and CPT, $C T x$ chemotherapy, $C P T$ cisplatin, $C R T x$ conformal RTx, DTX docetaxel, IMRTx intensity-modulated RTx, $R T x$ radiotherapy, $T M X$ tamoxifen, $T M Z$ temozolomide

Imaging: $D K I$ diffusion kurtosis imaging, $M W I$ myelin water imaging, NODDI neurite orientation dispersion and density imaging, $q M T$ quantitative magnetization transfer, $Q S M$ quantitative susceptibility mapping

Findings: $G M$ gray matter, $M K$ mean kurtosis, $M W I$ myelin water fraction, $N D I$ neurite density index, $N A W M$ normal-appearing WM, $O D I$ orientation dispersion index, Viso volume isotropy, $W M$ white matter

exist, and result consistency may rise with increasing numbers of studies. It is, therefore, crucial to harmonize study protocols and adhere to the highest quality of acquisition, analysis, and reporting for these techniques.
For NODDI, the inter-session reproducibility of NDI and ODI parameters is below 5\% voxel-wise and under $2 \%$ regionally. However, ISO has above $40 \%$ voxel-wise and above $10 \%$ regional repeatability [124]. The repeatability 
of DKI is not widely established, but the first results report a coefficient of variation between $4 \%$ and $5.2 \%$ for both RK and MK parameters [125].

\section{Clinical-imaging association}

Several studies investigated either cognition or qualityof-life, together with imaging changes without assessing their association. Either: (a) no cognitive or quality-of-life effects were found [39, 56, 83], (b) no imaging changes were detected [120], (c) the correlations between imaging and clinical findings were not reported [84, 86, 87].

Most studies reported an association of perfusion changes (CBF and CBV decrease, or $\mathrm{V}_{\mathrm{p}}, \mathrm{K}^{\text {trans }}$ increase) with cognitive or quality-of-life deterioration after brain radio(chemo) therapy. While no correlation of ASL-CBF with full-scale IQ was found in patients with posterior fossa tumors [53], a decrease in ${ }^{15} \mathrm{O}-\mathrm{H}_{2} \mathrm{O}$-PET signal at 6 months post-treatment correlated with retained cognitive function [51]. CBF and CBV decrease and mean vessel caliber increase obtained with DSC after SRS were more pronounced in patients with ECOG (Eastern Cooperative Oncology Group) performance score $>0$ on the pre-SRS baseline, hinting that the vasculature of those patients was already impaired at baseline and thus more susceptible to radiation-induced damage [44]. An acute increase of $\mathrm{V}_{\mathrm{p}}$ in the left temporal and frontal lobes and $\mathrm{K}^{\text {trans }}$ in the left frontal lobe was correlated with decreased verbal learning rates, and $\mathrm{K}^{\text {trans }}$ also with decreased recall scores [47]. $\mathrm{K}^{\text {trans }}$ changes in the hippocampus 1 month post-RTx were correlated with memory function at 6 months $(r=-0.95, p<0.0006)$ and 18 months $(r=-0.88, p<0.02)$ [49]. In breast cancer patients after CTx, ASL-CBF increased and this negatively correlated with a decrease in alerting network score $(-0.452<r<-0.550)$ and in the executive control network $(0.507<r<0.680)$ [55]. An increase in frontal-cortex CBF from ${ }^{15} \mathrm{O}-\mathrm{H}_{2} \mathrm{O}$-PET measurements was associated with symptoms of CTx-induced peripheral neuropathy at 1 month but not at 1 year after therapy [57].

The metabolic changes reported in brain-RTx patients correlated with a decrease in cognitive performance in most studies. NAA/Cr in corpus callosum after 1 month correlated positively with verbal fluency score and visuospatial functioning at 6 months, while $\mathrm{Cho} / \mathrm{Cr}$ correlated negatively with the memory functioning score [79]. Hippocampal NAA/Cr correlated positively with the visuospatial memory test scores $(r=0.66 ; p=0.008)$ [78]. And choline levels in NAWM correlated positively with IQ in pediatric patients 10 years after therapy [69]. Brain spectroscopy changes and their correlation to cognitive changes in breast cancer patients were similar to that of patients undergoing brain irradiation. Multifactorial memory score correlated negatively with choline level $(r=-0.62, p=0.005)$ and
$\mathrm{mI}(r=-0.55, p=0.02)$, but not with NAA/Cho or NAA/ $\mathrm{mI} 5$ years after therapy. And no imaging correlations were found with the decreased executive function [85]. Auditory verbal learning scores correlated with NAA in posterior cingulate gyrus $\left(r^{2}=0.470-0.5, p<0.01\right)$ [88]. Finally, a higher global deficit score (GDS) was weakly associated with inflammation on TSPO-PET in the frontal lobe after CTx in breast cancer [94].

Regional decreases in glucose uptake positively correlated with cognitive function in three studies of breast cancer patients undergoing CTx. Rey-Osterrieth Complex Figure (ROCF) performance was correlated with glucose metabolism in the left inferior frontal gyrus [91] and in the posterior orbital gyrus [92]. Additionally, acute changes in glucose uptake in anterior temporal and medial frontal correlated positively with memory test scores [90]; however, neither of those studies presented treatment-related imaging changes in those regions $[90,91]$ or both increases and decreases in glucose uptake across different regions were reported [92]. Thus the validity of cognitive-imaging correlations should be investigated in the future in larger studies with multiple comparison corrections. A clear longitudinal decrease in FDG-PET SUV negatively correlated with scores from the Symptom Checklist-90-R 6 months after brain RTx [34].

Finally, association results between diffusion kurtosis and cognitive performance or quality-of-life scores varied between no correlation [118] and a correlation with Montreal Cognitive Assessment (MoCA) score as early as 6 months post-RCTx [116]. A stratification to decline and non-decline groups by MoCA test at 2 years showed higher diffusion kurtosis in WM at 1 and 3 months in the nondecline group, which received $20 \%$ lower radiation dose to the brain [126]. One of the rare studies that looked at baseline values reported that memory recover at follow-up correlated both with pre-operative NDI and NDI recovery on follow-up [113]. In survivors of pediatric germ cell tumors, mean kurtosis correlated positively with Karnofsky's performance score and IQ in several cortical regions, but not on the whole-brain level [117].

Most of the reviewed studies evaluated cognitive and quality-of-life changes using several tests often with several subdomains. However, the correlation with imaging biomarkers was not always corrected for multiple comparisons, possibly invalidating the positive findings. Only nine studies have either described that a proper correction for multiple comparisons was used [44, 51, 79, 90, 117] or examined a correlation with a single test only $[69,91,116,126]$.

\section{Clinical-imaging association discussion}

Approximately one-third of the reviewed studies contained reports on cognitive or quality-of-life changes, but one-third of those did not find any correlations with imaging findings 
or did not report them, mostly as no association between the change of cognitive scores and treatment was found. Despite the variable findings between studies, consistent effects of treatment on the NABT for most biomarkers could be found. For the studies including cognition or quality-of-life tests in addition to these imaging biomarkers, decline in these clinical scores consistently correlated with these biomarkers. For example, brain RTx was associated with perfusion decrease and BBB permeability increase, both correlating with cognitive decline. Paradoxically, breast cancer CTx resulted in perfusion increase but was still associated with cognitive decline. In MRS, NAA decreases, and choline increases were observed for both brain RTx and CTx in non-CNS tumors, which in turn correlated to cognitive decrease.

In general, a large number of cognition and quality-oflife tests were calculated per study and multiple comparison correction was not always applied, which can easily result in spurious findings. In combination with a legion of cancer and therapy combinations, different ways to image the brain, and arbitrary assessment intervals, this resulted in a manifold of potential experiments, which are difficult to compare. Therefore, no clear pattern of correlation of imaging findings with a specific cognitive sub-domain or a quality-of-life score could be confirmed. In the future, alignment of the techniques would be beneficial to permit confirmation of these pilot results in larger multi-center studies.

\section{Discussion}

In this systematic review, changes in normal-appearing brain tissue following cancer therapy were summarised, measured using different quantitative imaging techniques in either a cross-sectional or longitudinal design. Taken together, all studies mainly presented evidence on adverse effects of brain RTx in CNS tumors, CTx in tumors outside CNS, and antiangiogenic treatment in recurrent glioblastomas. Regarding CTx it is currently unknown how inhomogeneities in focal metabolism and vascularization of the brain affect the pharmaco-metabolite distribution and therefore adverse effects as revealed by imaging biomarkers. After cranial RTx, NABT showed perfusion decrease relatively consistently with all modalities after both RTx and combined RCTx, and with only a slight inverse correlation to dose. ${ }^{1} \mathrm{H}-\mathrm{MRS}$ very consistently reported a decrease of NAA, $\mathrm{Cr}$, and NAA/Cr, and an increase in Cho and Cho/Cr. There was some evidence of correlation to dose, as well as trends towards normalization of changes after several months. However, the effects of dose and anatomical locations of the measured changes are still understudied - mostly because the acquisitions were executed in a single voxel contralateral to the tumor-and future studies with multi-voxel MRS imaging are required to provide more insight. Also, the T1 times in normal tissue only decreased in a single study, and T2*, QSM, or qMT measurements were inconclusive. Only weak evidence for diffusion kurtosis decreases could be found.

In breast cancer patients after CTx, metabolic changes measured with ${ }^{1} \mathrm{H}$-MRS were similar to changes in patients undergoing brain RTx: NAA, Cr, and NAA/Cr decrease, and $\mathrm{Cho}$ and $\mathrm{Cho} / \mathrm{Cr}$ increase. Higher dosage of CTx and inclusion of hormone therapy aggravated these effects. Interestingly, perfusion increases were reported to correlate with cognitive decline. While this was shown both longitudinally and cross-sectionally in two independent studies using ASL, validation is still required to confirm the opposite effects compared with brain RTx. Additionally, no or inconclusive metabolic changes were observed with FDGPET, which could probably be explained by the use of global normalization of the values. Finally, inconclusive findings from advanced diffusion models were reported in patients receiving CTx for non-CNS tumors: one study reported neurite density increase, while two others reported increase and decrease of diffusion kurtosis—-see the summary in Table 6 .

\section{Recommendations}

Based on the finding of this systematic review further quantitative imaging studies should be encouraged, addressing the main study-design weaknesses: inhomogeneity of patient populations in terms of both tumor type and treatment; missing descriptive characteristics of study population and treatment details; missing details on the study timeline; not adhering to the acquisition, processing, and reporting standards of the imaging; and incomplete and thorough reporting of the findings. The modified-QUADAS- 2 criteria used to assess the published work in this review can serve as a guideline on how to improve the study design, and how to report the methodology and results in future studies aiming at reducing the risk of bias. The acquisition and processing should be performed and described according to current standards: ASL [127, 128], DSC [129], and MRS [98]. Moreover, normalization to whole-brain or low-dose regions can potentially mask changes as the entire NABT might be affected by the treatment. Using an intact brain region based on previous findings or using the full quantitative potential of the imaging techniques may reduce the risk of not detecting subtle changes. All reported MRI techniques are sensitive to tissue type, providing a different contrast and also different performance characteristics in GM, WM, and CSF. The task of ROI delineation should take this into account, and a detailed description of the delineation should be provided to ease the identification of potential biases. Lastly, including a power analysis with negative findings could help the interpretation of results, if the study population size was 
Table 6 Aggregated findings per sequence and tumor type

\begin{tabular}{|c|c|c|c|c|c|}
\hline Modality & Tumor/Treatment & Studies & Patients & Effects & wsCoV \\
\hline \multirow[t]{2}{*}{ DSC } & Brain/RTx & $4 / 5$ & $123 / 142$ & $\downarrow$ CBV $4.6-30 \%$ & \multirow[t]{2}{*}{$2.5-3.5 \%$} \\
\hline & Brain/BEV & $1 / 2$ & $18 / 43$ & $\downarrow$ CBF $20-30 \%$ & \\
\hline \multirow[t]{2}{*}{ ASL } & Breast/CTx & $3 / 3$ & $82 / 82$ & $\uparrow \mathrm{CBF} 7-12 \%$ & \multirow[t]{2}{*}{$6.6-14.89$} \\
\hline & Glioma III-IV/RCTx & $4 / 5$ & $123 / 142$ & $\downarrow \mathrm{CBF} 10-23 \%$ & \\
\hline DCE & Brain/RCTx & $3 / 5$ & $49 / 89$ & $\uparrow \mathrm{V}_{\mathrm{e}} 8-12 \%, \uparrow \mathrm{K}^{\operatorname{trans}} 52 \%$ & $7.7 \%$ \\
\hline Tc-99 m-HMPAO & Brain/RTx + SRS & $2 / 3$ & $31 / 42$ & $\downarrow \mathrm{CBF} 4-22.5 \%$ & $15 \%$ \\
\hline \multirow[t]{2}{*}{${ }^{1} \mathrm{H}-\mathrm{MRS}$} & Breast/CTx & $4 / 4$ & $79 / 79$ & $\downarrow$ NAA, NAA/Cr, or NAA/Cho $1-15 \%$ & \multirow[t]{2}{*}{$2.5-5.3 \%$} \\
\hline & Brain/RCTx & $12 / 13$ & $244 / 284$ & $\begin{array}{l}\downarrow \text { NAA/Cr 5-31\%, NAA/Cho } 15-19 \% \text {, } \\
\text { NAA 4-16\%; } \uparrow \text { Cho/Cr 4-20\% }\end{array}$ & \\
\hline FDG-PET & NHL/CTx & $1 / 2$ & $21 / 35$ & $\downarrow$ FDG $20 \%$ & $10 \%$ \\
\hline DKI & Non-CNS/RCTx & $3 / 4$ & $130 / 169$ & $\downarrow$ MK $11-34 \%$ & $4-5.2 \%$ \\
\hline
\end{tabular}

Tumor type: $C N S$ central nervous system, $N H L$ non-Hodgkin lymphoma

Treatment type: $B E V$ bevacizumab, $C T x$ chemotherapy, $R T x$ radiotherapy, $R C T x$ radiochemotherapy

Imaging: $A S L$ arterial spin labeling, $D K I$ diffusion kurtosis imaging, $D S C$ dynamic susceptibility contrast, $D C E$ dynamic contrast enhanced, $F D G$ fluoro-deoxy-glucose, $M R S$ magnetic resonance spectroscopy

Findings: $C B F$ cerebral blood flow, $C B V$ cerebral blood volume, $C h o$ choline, $C r$ creatine, $M K$ mean kurtosis, $N A A N$-acetyl aspartate, $K^{\text {trans }}$ extravascular and $V_{e}$ extracellular fractional volume, $w s C o V$ within-subject coefficient of variation

Summary results are given for each imaging technique and tumor type when the majority of studies that reported an observed parameter had results in concordance. Single studies, or studies where majority of findings were inconclusive or not in an agreement were not reported. The total number of studies and patients in concordance-out of the total number of studies and subject reporting comparable results-are given. Lastly, the within-subject across session coefficient of variation is provided to provide a reference of repeatability in healthy volunteers

large enough to observe significant changes, especially in studies with several treatment subgroups.

A general concern is that many studies were explorative only, with small sample size, and did not show statistically significant changes. Still, interesting trends were reported, and the effect sizes may provide a good starting point for power analyses needed in the preparation of larger future studies. Also for some techniques, only a few studies were available, partly caused by the limited availability of quantitative imaging [19]. The general challenge of these kinds of studies is to separate the effect of treatment from the effect of having a tumor, which puts further pressure on the quality of the study design to minimize confounders. At the same time, further research is needed to separate the individual effects of different types of chemo-, radio-, and immunotherapies, as well as their synergies. While specific study design, like head-and-neck tumors or proton vs photon radiochemotherapy, can help to separate the tumor from radiation effects or radio- from chemotherapy, respectively, more evidence from pooled large studies will be needed. Several community-driven initiatives, for example, Open Source Initiative for Perfusion Imaging (OSIPI-www.osipi.org) and Glioma MR Imaging 2.0 (GliMR, COST Action CA18206) [20], aim at making knowledge and tools for acquisition and analysis of quantitative MRI widely available to advance the field. Additionally, pooling datasets might be indispensable to investigate subtle therapy effects and their regional variations, and to disentangle the interaction of different treatments, possibly with the help of machine learning methods. To this end, it is necessary to obtain patients' consent to share their data in a secured, controlled manner, ensuring GDPR compliance [130], and using the standardized BIDS format [131] following existing extensions for e.g. PET [132] or ASL [133]. Finally, it is important to consider that brains already differ in their capacity to cope with therapy-related damage prior to cancer therapy, which can be considered a traumatic event. For example, patients with pre-existent small vessel disease or changes leading to subclinical dementia might have a decreased chance to recover from acute cancer therapy effects on the brain compared with an otherwise healthy individual. Here, lifestyle and age, presence of radio-necrosis, but also the baseline status of the biomarker should be considered as co-factors influencing the biomarker gradient when monitoring cancer therapy effects on the brain.

To summarize the recommendations, we advise that future studies investigating the normal tissue changes following cancer therapy should:

- Provide a complete description of the study population, treatment details and timeline, as well as details of acquisition and processing - the modified-QUADAS-2 criteria in supplementary materials provide guidance for this;

- adhere to the latest recommendations for image acquisition and processing-ASL [127, 128], DSC [129, 134, 135], MRS [98]; 
- avoid mixed cohorts with inhomogeneous tumor and treatment types;

- correct for multiple comparisons and perform a power analysis to avoid spurious findings and to help interpret negative findings;

- support community efforts for data sharing and collaboration (e.g. OSIPI, BIDS [131], OpenNeuro [136], GliMR [20], or ENBIT - www.enbit.ac.uk) to enable future data pooling in larger studies.

\section{Limitations}

This review has several limitations. First, not all quantitative imaging techniques were represented. For example, blood microcirculation measurement with Intravoxel Incoherent Motion (IVIM) [137], or amino-acid measured glucose metabolism with chemical exchange saturation transfer (CEST) could yield interesting results. However, no such publications matching the inclusion criteria were identified during the search. Second, some of the reviewed studies were primarily focusing on the tumor and NABT changes were reported for the sake of normalization or normalization reproducibility. Thus, the quality of the reporting on these side effects was not always optimal, not being the main focus of the study. However, NABT changes in the vicinity of the tumor were ignored so the reported results were not influenced by tumor growth, infiltration, or radionecrosis. Still, besides under-reporting, there is no reason to believe that the reported values are structurally biased. Third, we did not compare the results of the quantitative imaging methods with the conventional structural imaging biomarkers. From the dementia field, there is evidence that physiological and metabolic biomarkers can pick up changes in brain pathology earlier than structural biomarkers $[138,139]$. We hypothesize that this is also the case for RCTx-induced tissue damage, but this needs to be proven yet. Fourth, the acquisition and evaluation of the advanced MRI techniques reviewed here is typically more complex than is the case for standard MRI. There are large differences between the available sequences [61] and models [62] used for their processing and quantification, leading to substantial instrumental variability [134] of the measured parameters. Currently, there are several initiatives that try to propose standards for acquisition [127], processing
[128], reference regions [135], and quantification [129] of the advanced MRI data for different sequences. However, most of these were proposed only after the reviewed studies were published, which further complicates a fair comparison of fidelity of individual results presented here. Finally, it should be acknowledged that group-effect results do not guarantee clinical benefit on the single-patient level. This is expected to be especially challenging for biomarkers with high temporal variability-such as physiological fluctuations in cerebral blood flow_but the effect size may even be too small for existing structural biomarkers; especially in the early stages of treatment-induced damage. Therefore, this needs to be carefully studied in the future.

\section{Conclusion}

Quantitative imaging techniques have the potential to detect cancer therapy-related changes in the NABT and correlate with long-term cognitive decline or quality-of-life deterioration. To date, a relatively small number of studies are published that may provide an estimate of the effect size of treatment. However, the evolution of these quantitative changes in time and dependency on dosing and location is still unclear and needs to be evaluated to establish quantitative imaging as an early marker of tissue damage or a predictor of long-term cognitive outcome. Regardless of its limitations, all reviewed imaging techniques showed promise to measure treatment-related damage in NABT, and most evidence is available for ${ }^{1} \mathrm{H}$-MRS and perfusion imaging with DSC and ASL. However, additional care for correct image acquisition, analysis, and interpretation is highly recommended, especially with respect to reaching sufficient statistical power during study planning. Standardizing methodology and pooling of datasets or adding dedicated imaging sequences to existing large-scale studies might be necessary to address this shortcoming, especially for less common imaging techniques.

Supplementary Information The online version contains supplementary material available at https://doi.org/10.1007/s10334-021-00985-2.

Acknowledgements This publication is part of the COST Action CA18206 Glioma MR Imaging 2.0, supported by COST (European Cooperation in Science and Technology) www.cost.eu; www.glimr.eu.

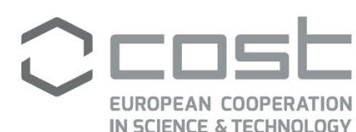
IN SCIENCE \& TECHNOLOGY
Funded by the Horizon 2020 Framework Programme of the European Union

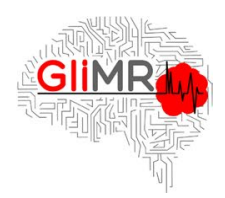


Author contributions JP: Study conception and design, acquisition of data, analysis and interpretation of data, drafting of manuscript, critical revision. LH: Study conception and design, acquisition of data, analysis and interpretation of data. PN: Acquisition of data, analysis and interpretation of data, drafting of manuscript, critical revision. EW: Acquisition of data, analysis and interpretation of data, drafting of manuscript, critical revision. GS: Acquisition of data, analysis and interpretation of data, drafting of manuscript, critical revision. JK: Acquisition of data, analysis and interpretation of data, drafting of manuscript. MC: Acquisition of data, analysis and interpretation of data, drafting of manuscript, critical revision. REN: Acquisition of data, analysis and interpretation of data. L-AF: Acquisition of data, analysis and interpretation of data. PC: Drafting of manuscript and critical revision. PDWH: Critical revision. FB: Critical revision. CP: Acquisition of data, analysis and interpretation of data, drafting of manuscript, critical revision. ML: Acquisition of data, analysis and interpretation of data, critical revision. SD: Acquisition of data, analysis and interpretation of data, drafting of manuscript, critical revision. RJ: Acquisition of data, analysis and interpretation of data. HJMMM: Drafting of manuscript and critical revision. FBP: Acquisition of data, analysis and interpretation of data, drafting of manuscript, critical revision. KEE: Acquisition of data, analysis and interpretation of data, drafting of manuscript, critical revision. VCK: Study conception and design, acquisition of data, analysis and interpretation of data, drafting of manuscript, critical revision.

Funding Open Access funding enabled and organized by Projekt DEAL. This project is funded by European Cooperation in Science and Technology, CA18206, Jan Petr.

Open Access This article is licensed under a Creative Commons Attribution 4.0 International License, which permits use, sharing, adaptation, distribution and reproduction in any medium or format, as long as you give appropriate credit to the original author(s) and the source, provide a link to the Creative Commons licence, and indicate if changes were made. The images or other third party material in this article are included in the article's Creative Commons licence, unless indicated otherwise in a credit line to the material. If material is not included in the article's Creative Commons licence and your intended use is not permitted by statutory regulation or exceeds the permitted use, you will need to obtain permission directly from the copyright holder. To view a copy of this licence, visit http://creativecommons.org/licenses/by/4.0/.

\section{References}

1. Makale MT, McDonald CR, Hattangadi-Gluth JA, Kesari S (2017) Mechanisms of radiotherapy-associated cognitive disability in patients with brain tumours. Nat Rev Neurol 13:52-64

2. Douw L, Klein M, Fagel SS, van den Heuvel J, Taphoorn MJ, Aaronson NK, Postma TJ, Vandertop WP, Mooij JJ, Boerman RH, Beute GN, Sluimer JD, Slotman BJ, Reijneveld JC, Heimans JJ (2009) Cognitive and radiological effects of radiotherapy in patients with low-grade glioma: long-term follow-up. Lancet Neurol 8:810-818

3. Ahles TA, Root JC, Ryan EL (2012) Cancer- and cancer treatment-associated cognitive change: an update on the state of the science. J Clin Oncol 30:3675-3686

4. Ahles TA, Saykin AJ, Noll WW, Furstenberg CT, Guerin S, Cole B, Mott LA (2003) The relationship of APOE genotype to neuropsychological performance in long-term cancer survivors treated with standard dose chemotherapy. Psychooncology $12: 612-619$
5. Small BJ, Rawson KS, Walsh E, Jim HSL, Hughes TF, Iser L, Andrykowski MA, Jacobsen PB (2011) Catechol-O-methyltransferase genotype modulates cancer treatment-related cognitive deficits in breast cancer survivors. Cancer 117:1369-1376

6. Sleurs C, Madoe A, Lagae L, Jacobs S, Deprez S, Lemiere J, Uyttebroeck A (2019) Genetic modulation of neurocognitive development in cancer patients throughout the lifespan: a systematic review. Neuropsychol Rev 29:190-219

7. Deprez S, Kesler SR, Saykin AJ, Silverman DHS, de Ruiter MB, McDonald BC (2018) International cognition and cancer task force recommendations for neuroimaging methods in the study of cognitive impairment in Non-CNS cancer patients. J Natl Cancer Inst 110:223-231

8. Karunamuni R, Bartsch H, White NS, Moiseenko V, Carmona R, Marshall DC, Seibert TM, McDonald CR, Farid N, Krishnan A, Kuperman J, Mell L, Brewer JB, Dale AM, Hattangadi-Gluth JA (2016) Dose-dependent cortical thinning after partial brain irradiation in high-grade glioma. Int J Radiat Oncol Biol Phys 94:297-304

9. Petr J, Platzek I, Hofheinz F, Mutsaerts HJMM, Asllani I, van Osch MJP, Seidlitz A, Krukowski P, Gommlich A, BeuthienBaumann B, Jentsch C, Maus J, Troost EGC, Baumann M, Krause M, van den Hoff J (2018) Photon vs. proton radiochemotherapy: effects on brain tissue volume and perfusion. Radiother Oncol 128:121-127

10. Li M, Caeyenberghs K (2018) Longitudinal assessment of chemotherapy-induced changes in brain and cognitive functioning: a systematic review. Neurosci Biobehav Rev 92:304-317

11. Nagtegaal SHJ, David S, van der Boog ATJ, Leemans A, Verhoeff JJC (2019) Changes in cortical thickness and volume after cranial radiation treatment: a systematic review. Radiother Oncol $135: 33-42$

12. Kłos J, van Laar PJ, Sinnige PF, Enting RH, Kramer MCA, van der Weide HL, van Buchem MA, Dierckx RAJO, Borra RJH, van der Hoorn A (2019) Quantifying effects of radiotherapy-induced microvascular injury; review of established and emerging brain MRI techniques. Radiother Oncol 140:41-53

13. Deprez S, Billiet T, Sunaert S, Leemans A (2013) Diffusion tensor MRI of chemotherapy-induced cognitive impairment in nonCNS cancer patients: a review. Brain Imaging Behav 7:409-435

14. Sousa H, Almeida S, Bessa J, Pereira MG (2020) The developmental trajectory of cancer-related cognitive impairment in breast cancer patients: a systematic review of longitudinal neuroimaging studies. Neuropsychol Rev 30:287-309

15. Witzmann K, Raschke F, Troost EGC (2021) MR image changes of normal-appearing brain tissue after radiotherapy. Cancers (Basel) 13:1573

16. Simó M, Rifà-Ros X, Rodriguez-Fornells A, Bruna J (2013) Chemobrain: a systematic review of structural and functional neuroimaging studies. Neurosci Biobehav Rev 37:1311-1321

17. de Ruiter MB, Schagen SB (2013) Functional MRI studies in non-CNS cancers. Brain Imaging Behav 7:388-408

18. Ajithkumar T, Price S, Horan G, Burke A, Jefferies S (2017) Prevention of radiotherapy-induced neurocognitive dysfunction in survivors of paediatric brain tumours: the potential role of modern imaging and radiotherapy techniques. Lancet Oncol 18:e91-e100

19. Manfrini E, Smits M, Thust S, Geiger S, Bendella Z, Petr J, Solymosi L, Keil VC (2021) From research to clinical practice: a European neuroradiological survey on quantitative advanced MRI implementation. Eur Radiol. https://doi.org/10.1007/ s00330-020-07582-2

20. Clement P, Booth T, Borovečki F, Emblem KE, Figueiredo P, Hirschler L, Jančálek R, Keil VC, Maumet C, Özsunar Y, Pernet C, Petr J, Pinto J, Smits M, Warnert EAH (2021) GliMR: 
cross-border collaborations to promote advanced MRI biomarkers for glioma. J Med Biol Eng 41:115-125

21. Moher D, Liberati A, Tetzlaff J, Altman DG (2009) Preferred reporting items for systematic reviews and meta-analyses: The PRISMA statement. PLoS Med 6:e1000097

22. Moher D, Shamseer L, Clarke M, Ghersi D, Liberati A, Petticrew M, Shekelle P, Stewart LA (2015) Preferred reporting items for systematic review and meta-analysis protocols (PRISMA-P) 2015 statement. Syst Rev 4:1

23. Methley AM, Campbell S, Chew-Graham C, McNally R, Cheraghi-Sohi S (2014) PICO, PICOS and SPIDER: a comparison study of specificity and sensitivity in three search tools for qualitative systematic reviews. BMC Health Serv Res 14:579

24. Whiting PF (2011) QUADAS-2: a revised tool for the quality assessment of diagnostic accuracy studies. Ann Intern Med 155:529

25. Peña LA, Fuks Z, Kolesnick RN (2000) Radiation-induced apoptosis of endothelial cells in the murine central nervous system: protection by fibroblast growth factor and sphingomyelinase deficiency. Cancer Res 60:321-327

26. Price RE, Langford LA, Jackson EF, Stephens LC, Tinkey PT, Ang KK (2001) Radiation-induced morphologic changes in the rhesus monkey (Macaca mulatta) brain. J Med Primatol 30:81-87

27. Brown WR, Thore CR, Moody DM, Robbins ME, Wheeler KT (2005) Vascular damage after fractionated whole-brain irradiation in rats. Radiat Res 164:662-668

28. Reinhold HS, Calvo W, Hopewell JW, van der Berg AP (1990) Development of blood vessel-related radiation damage in the fimbria of the central nervous system. Int J Radiat Oncol Biol Phys 18:37-42

29. Emblem KE, Larsson C, Groote IR, Bjørnerud A (2020) MRI perfusion Techniques. neuroimaging techniques in clinical practice. Springer International Publishing, Cham, pp 141-164

30. Baas KPA, Petr J, Kuijer JPA, Nederveen AJ, Mutsaerts HJMM, van de Ven KCC (2021) Effects of acquisition parameter modifications and field strength on the reproducibility of brain perfusion measurements using arterial spin-labeling. Am J Neuroradiol 42:109-115

31. Heijtel DFR, Mutsaerts HJMM, Bakker E, Schober P, Stevens MF, Petersen ET, van Berckel BNM, Majoie CBLM, Booij J, van Osch MJP, VanBavel E, Boellaard R, Lammertsma AA, Nederveen AJ (2014) Accuracy and precision of pseudo-continuous arterial spin labeling perfusion during baseline and hypercapnia: a head-to-head comparison with $15 \mathrm{O} \mathrm{H} 2 \mathrm{O}$ positron emission tomography. Neuroimage 92:182-192

32. Taki S, Higashi K, Oguchi M, Tamamura H, Tsuji S, Ohta K, Tonami H, Yamamoto I, Okamoto K, Iizuka H (2002) Changes in regional cerebral blood flow in irradiated regions and normal brain after stereotactic radiosurgery. Ann Nucl Med 16:273-277

33. Gülaldi NCM, Kostakoğlu L, Uzal D, Hayran M, Elahi N, Uysal U, Aktaş A, Atahan L, Bekdik C (2000) Impact of radiotherapy on normal brain tissue: Semi-automated quantification of decrease in perfusion. Ann Nucl Med 14:17-23

34. Hahn CA, Zhou SM, Raynor R, Tisch A, Light K, Shafman T, Wong T, Kirkpatrick J, Turkington T, Hollis D, Marks LB (2009) Dose-dependent effects of radiation therapy on cerebral blood flow, metabolism, and neurocognitive dysfunction. Int J Radiat Oncol Biol Phys 73:1082-1087

35. Véra P, Rohrlich P, Stiévenart JL, Elmaleh M, Duval M, Bonnin F, Bok B, Vilmer E (1999) Contribution of single-photon emission computed tomography in the diagnosis and follow-up of CNS toxicity of a cytarabine-containing regimen in pediatric leukemia. J Clin Oncol 17:2804-2804

36. Wenz F, Rempp K, Heß T, Debus J, Brix G, Engenhart R, Knopp MV, Van Kaick G, Wannenmacher M (1996) Effect of radiation on blood volume in low-grade astrocytomas and normal brain tissue: quantification with dynamic susceptibility contrast MR imaging. Am J Roentgenol 166:187-193

37. Fuss M, Wenz F, Scholdei R, Essig M, Debus J, Knopp MV, Wannenmacher M (2000) Radiation-induced regional cerebral blood volume (rCBV) changes in normal brain and low-grade astrocytomas: quantification and time and dose-dependent occurrence. Int J Radiat Oncol Biol Phys 48:53-58

38. Price SJ, Jena R, Green HAL, Kirkby NF, Lynch AG, Coles CE, Pickard JD, Gillard JH, Burnet NG (2007) Early radiotherapy dose response and lack of hypersensitivity effect in normal brain tissue: a sequential dynamic susceptibility imaging study of cerebral perfusion. Clin Oncol 19:577-587

39. Bian Y, Meng L, Peng J, Li J, Wei R, Huo L, Yang H, Wang Y, Fu J, Shen L, Hong J (2019) Effect of radiochemotherapy on the cognitive function and diffusion tensor and perfusion weighted imaging for high-grade gliomas: a prospective study. Sci Rep $9: 1-10$

40. Jakubovic R, Sahgal A, Ruschin M, Pejović-Milić A, Milwid R, Aviv RI (2015) Non tumor perfusion changes following stereotactic radiosurgery to brain metastases. Technol Cancer Res Treat 14:497-503

41. Lee MC, Cha S, Chang SM, Nelson SJ (2005) Dynamic susceptibility contrast perfusion imaging of radiation effects in normalappearing brain tissue: changes in the first-pass and recirculation phases. J Magn Reson Imaging 21:683-693

42. Weber MA, Thilmann C, Lichy MP, Günther M, Delorme S, Zuna I, Bongers A, Schad LR, Debus J, Kauczor HU, Essig M, Schlemmer HP (2004) Assessment of irradiated brain metastases by means of arterial spin-labeling and dynamic susceptibilityweighted contrast-enhanced perfusion MRI: initial results. Invest Radiol 39:277-287

43. Fahlström M, Blomquist E, Nyholm T, Larsson EM (2018) Perfusion magnetic resonance imaging changes in normal appearing brain tissue after radiotherapy in glioblastoma patients may confound longitudinal evaluation of treatment response. Radiol Oncol 52:143-151

44. Nilsen LB, Digernes I, Grøvik E, Saxhaug C, Latysheva A, Geier O, Breivik B, Sætre DO, Jacobsen KD, Helland Å, Emblem KE (2020) Responses in the diffusivity and vascular function of the irradiated normal brain are seen up until 18 months following SRS of brain metastases. Neuro-Oncol Adv 2:1-10

45. Singh R, Kesavabhotla K, Kishore SA, Zhou Z, Tsiouris AJ, Filippi CG, Boockvar JA, Kovanlikaya I (2016) Dynamic susceptibility contrast-enhanced $\mathrm{mr}$ perfusion imaging in assessing recurrent glioblastoma response to superselective intra-arterial bevacizumab therapy. Am J Neuroradiol 37:1838-1843

46. Stadlbauer A, Pichler P, Karl M, Brandner S, Lerch C, Renner B, Heinz G (2015) Quantification of serial changes in cerebral blood volume and metabolism in patients with recurrent glioblastoma undergoing antiangiogenic therapy. Eur J Radiol 84:1128-1136

47. Cao Y, Tsien CI, Sundgren PC, Nagesh V, Normolle D, Buchtel H, Junck L, Lawrence TS (2009) Dynamic contrast-enhanced magnetic resonance imaging as a biomarker for prediction of radiation-induced neurocognitive dysfunction. Clin Cancer Res 15:1747-1754

48. Fahlström M, Fransson S, Blomquist E, Nyholm T, Larsson E-M (2018) Dynamic contrast-enhanced magnetic resonance imaging may act as a biomarker for vascular damage in normal appearing brain tissue after radiotherapy in patients with glioblastoma. Acta Radiol Open 7:205846011880881

49. Farjam R, Pramanik P, Aryal MP, Srinivasan A, Chapman CH, Tsien CI, Lawrence TS, Cao Y (2015) A radiation-induced hippocampal vascular injury surrogate marker predicts late neurocognitive dysfunction. Int J Radiat Oncol Biol Phys 93:908-915

50. Artzi M, Liberman G, Blumenthal DT, Bokstein F, Aizenstein O, Ben Bashat D (2018) Repeatability of dynamic contrast enhanced 
$\mathrm{v} p$ parameter in healthy subjects and patients with brain tumors. J Neurooncol 140:727-737

51. Wong P, Leppert IR, Roberge D, Boudam K, Brown PD, Muanza T, Bruce Pike G, Chankowsky J, Mihalcioiu C (2016) A pilot study using dynamic contrast enhanced-MRI as a response biomarker of the radioprotective effect of memantine in patients receiving whole brain radiotherapy. Oncotarget 7:50986-50996

52. Wang P, Li J, Diao Q, Lin YK, Zhang J, Li L, Yang G, Fang X, Li X, Chen YQ, Zheng L, Lu G (2016) Assessment of glioma response to radiotherapy using 3D pulsed-continuous arterial spin labeling and 3D segmented volume. Eur J Radiol 85:1987-1992

53. Li MD, Forkert ND, Kundu P, Ambler C, Lober RM, Burns TC, Barnes PD, Gibbs IC, Grant GA, Fisher PG, Cheshier SH, Campen CJ, Monje M, Yeom KW (2017) Brain perfusion and diffusion abnormalities in children treated for posterior fossa brain tumors. J Pediatr 185:173-180.e3

54. Andre JB, Nagpal S, Hippe DS, Ravanpay AC, Schmiedeskamp H, Bammer R, Palagallo GJ, Recht L, Zaharchuk G (2015) Cerebral blood flow changes in glioblastoma patients undergoing bevacizumab treatment are seen in both tumor and normal brain. Neuroradiol J 28:112-119

55. Chen X, He X, Tao L, Cheng H, Li J, Zhang J, Qiu B, Yu Y, Wang K (2017) The attention network changes in breast cancer patients receiving neoadjuvant chemotherapy: evidence from an arterial spin labeling perfusion study. Sci Rep 7:1-9

56. Nudelman KNH, Wang Y, McDonald BC, Conroy SK, Smith DJ, West JD, O'Neill DP, Schneider BP, Saykin AJ (2014) Altered cerebral blood flow one month after systemic chemotherapy for breast cancer: a prospective study using pulsed arterial spin labeling MRI perfusion. PLoS ONE 9:e96713

57. Nudelman KNH, McDonald BC, Wang Y, Smith DJ, West JD, O'Neill DP, Zanville NR, Champion VL, Schneider BP, Saykin AJ (2016) Cerebral perfusion and gray matter changes associated with chemotherapy-induced peripheral neuropathy. J Clin Oncol 34:677-683

58. Jonsson C, Pagani M, Johansson L, Thurfjell L, Jacobsson H, LARSSON SA, (2000) Reproducibility and repeatability of 99Tcm-HMPAO rCBF SPET in normal subjects at rest using brain atlas matching. Nucl Med Commun 21:9-18

59. Jafari-Khouzani K, Emblem KE, Kalpathy-Cramer J, Bjørnerud A, Vangel MG, Gerstner ER, Schmainda KM, Paynabar K, Wu O, Wen PY, Batchelor T, Rosen B, Stufflebeam SM (2015) Repeatability of cerebral perfusion using dynamic susceptibility contrast MRI in glioblastoma patients. Transl Oncol 8:137-146

60. Shukla-Dave A, Obuchowski NA, Chenevert TL, Jambawalikar S, Schwartz LH, Malyarenko D, Huang W, Noworolski SM, Young RJ, Shiroishi MS, Kim H, Coolens C, Laue H, Chung C, Rosen M, Boss M, Jackson EF (2019) Quantitative imaging biomarkers alliance (QIBA) recommendations for improved precision of DWI and DCE-MRI derived biomarkers in multicenter oncology trials. J Magn Reson Imaging 49:e101-e121

61. Wu B, Lou X, Wu X, Ma L (2014) Intra- and interscanner reliability and reproducibility of 3D whole-brain pseudo-continuous arterial spin-labeling MR perfusion at 3T. J Magn Reson Imaging 39:402-409

62. Inglese M, Ordidge KL, Honeyfield L, Barwick TD, Aboagye EO, Waldman AD, Grech-Sollars M (2019) Reliability of dynamic contrast-enhanced magnetic resonance imaging data in primary brain tumours: a comparison of Tofts and shutter speed models. Neuroradiology 61:1375-1386

63. Buonocore MH, Maddock RJ (2015) Magnetic resonance spectroscopy of the brain: a review of physical principles and technical methods. Rev Neurosci 26:609-632
64. Wang T, Xiao S, Li X, Ding B, Ling H, Chen K, Fang Y (2012) Using proton magnetic resonance spectroscopy to identify mild cognitive impairment. Int Psychogeriatrics 24:19-27

65. Ahles TA, Saykin AJ (2007) Candidate mechanisms for chemotherapy-induced cognitive changes. Nat Rev Cancer 7:192-201

66. Kaplan SV, Limbocker RA, Gehringer RC, Divis JL, Osterhaus GL, Newby MD, Sofis MJ, Jarmolowicz DP, Newman BD, Mathews TA, Johnson MA (2016) Impaired brain dopamine and serotonin release and uptake in wistar rats following treatment with carboplatin. ACS Chem Neurosci 7:689-699

67. Werry EL, Bright FM, Piguet O, Ittner LM, Halliday GM, Hodges JR, Kiernan MC, Loy CT, Kril JJ, Kassiou M (2019) Recent developments in TSPO PET imaging as a biomarker of neuroinflammation in neurodegenerative disorders. Int J Mol Sci 20:3161

68. Chernov MF, Hayashi M, Izawa M, Nakaya K, Tamura N, Ono Y, Abe K, Usukura M, Yoshida S, Nakamura R, Suzuki T, Muragaki Y, Iseki H, Kubo O, Hori T, Takakura K (2009) Dynamics of metabolic changes in intracranial metastases and distant normalappearing brain tissue after stereotactic radiosurgery: a serial proton magnetic resonance spectroscopy study. Neuroradiol $\mathbf{J}$ 22:58-71

69. Davidson A, Tait DM, Payne GS, Hopewell JW, Leach MO, Watson M, MacVicar ADL, Britton JA, Ashley S (2000) Magnetic resonance spectroscopy in the evaluation of neurotoxicity following cranial irradiation for childhood cancer. Br J Radiol $73: 421-424$

70. Usenius T, Usenius JP, Tenhunen M, Vainio P, Johansson R, Soimakallio S, Kauppinen R (1995) Radiation-induced changes in human brain metabolites as studied by $1 \mathrm{H}$ nuclear magnetic resonance spectroscopy in vivo. Int J Radiat Oncol Biol Phys 33:719-724

71. Rutkowski T, Tarnawski R, Sokol M, Maciejewski B (2003) 1H-MR spectroscopy of normal brain tissue before and after postoperative radiotherapy because of primary brain tumors. Int J Radiat Oncol Biol Phys 56:1381-1389

72. Kaminaga T, Shirai K (2005) Radiation-induced brain metabolic changes in the acute and early delayed phase detected with quantitative proton magnetic resonance spectroscopy. J Comput Assist Tomogr 29:293-297

73. Lee MC, Pirzkall A, McKnight TR, Nelson SJ (2004) 1H-MRSI of radiation effects in normal-appearing white matter: dosedependence and impact on automated spectral classification. J Magn Reson Imaging 19:379-388

74. Rueckriegel SM, Driever PH, Bruhn H (2012) Supratentorial neurometabolic alterations in pediatric survivors of posterior fossa tumors. Int J Radiat Oncol Biol Phys 82:1135-1141

75. Waldrop SM, Davis PC, Padgett CA, Shapiro MB, Morris R (1998) Treatment of brain tumors in children is associated with abnormal MR spectroscopic ratios in brain tissue remote from the tumor site. Am J Neuroradiol 19:963-970

76. Chawla S, Wang S, Kim S, Sheriff S, Lee P, Rengan R, Lin A, Melhem E, Maudsley A, Poptani H (2015) Radiation injury to the normal brain measured by $3 \mathrm{D}$-echo-planar spectroscopic imaging and diffusion tensor imaging: initial experience. J Neuroimaging 25:97-104

77. Pospisil P, Kazda T, Bulik M, Dobiaskova M, Burkon P, Hynkova L, Slampa P, Jancalek R (2015) Hippocampal proton MR spectroscopy as a novel approach in the assessment of radiation injury and the correlation to neurocognitive function impairment: Initial experiences. Radiat Oncol 10:1-9

78. Pospisil P, Kazda T, Hynkova L, Bulik M, Dobiaskova M, Burkon P, Laack NN, Slampa P, Jancalek R (2017) Post-WBRT cognitive impairment and hippocampal neuronal depletion measured 
by in vivo metabolic MR spectroscopy: Results of prospective investigational study. Radiother Oncol 122:373-379

79. Alirezaei Z, Amouheidari A, Hassanpour M, Davanian F, Iraji S, Shokrani P, Nazem-Zadeh MR (2021) Early detection of radiation-induced injury and prediction of cognitive deficit by MRS metabolites in radiotherapy of low-grade glioma. Biomed Res Int. https://doi.org/10.1155/2021/6616992

80. Estève F, Rubin C, Grand S, Kolodié H, Le Bas JF (1998) Transient metabolic changes observed with proton MR spectroscopy in normal human brain after radiation therapy. Int J Radiat Oncol Biol Phys 40:279-286

81. Sundgren PC, Nagesh V, Elias A, Tsien C, Junck L, Hassan DMG, Lawrence TS, Chenevert TL, Rogers L, McKeever P, Cao Y (2009) Metabolic alterations: A biomarker for radiation induced normal brain injury-an MR spectroscopy study. J Magn Reson Imaging 29:291-297

82. Virta A, Patronas N, Raman R, Dwyer A, Barnett A, Bonavita S, Tedeschi G, Lundbom N (2000) Spectroscopic imaging of radiation-induced effects in the white matter of glioma patients. Magn Reson Imaging 18:851-857

83. Davidson A, Payne G, Leach MO, McVicar D, Britton JM, Watson M, Tait DM (2000) Proton magnetic resonance spectroscopy (H-MRS) of the brain following high-dose methotrexate treatment for childhood cancer. Med Pediatr Oncol 35:28-34

84. Follin C, Erfurth EM, Johansson A, Lätt J, Sundgren PC, Österberg K, Spulber G, Mannfolk P, Björkman-Burtscher IM (2016) Impaired brain metabolism and neurocognitive function in childhood leukemia survivors despite complete hormone supplementation in adulthood. Psychoneuroendocrinology 73:157-165

85. Kesler SR, Watson C, Koovakkattu D, Lee C, O'Hara R, Mahaffey ML, Wefel JS (2013) Elevated prefrontal myo-inositol and choline following breast cancer chemotherapy. Brain Imaging Behav 7:501-510

86. De Ruiter MB, Reneman L, Boogerd W, Veltman DJ, Caan M, Douaud G, Lavini C, Linn SC, Boven E, Van Dam FSAM, Schagen SB (2012) Late effects of high-dose adjuvant chemotherapy on white and gray matter in breast cancer survivors: converging results from multimodal magnetic resonance imaging. Hum Brain Mapp 33:2971-2983

87. Stouten-Kemperman MM, de Ruiter MB, Koppelmans V, Boogerd W, Reneman L, Schagen SB (2015) Neurotoxicity in breast cancer survivors $\geq 10$ years post-treatment is dependent on treatment type. Brain Imaging Behav 9:275-284

88. Tong T, Lu H, Zong J, Lv Q, Chu X (2020) Chemotherapyrelated cognitive impairment in patients with breast cancer based on MRS and DTI analysis. Breast Cancer 27:893-902

89. Hattingen E, Jurcoane A, Bähr O, Rieger J, Magerkurth J, Anti S, Steinbach JP, Pilatus U (2011) Bevacizumab impairs oxidative energy metabolism and shows antitumoral effects in recurrent glioblastomas: a 31P/ 1H MRSI and quantitative magnetic resonance imaging study. Neuro Oncol 13:1349-1363

90. Pomykala KL, Ganz PA, Bower JE, Kwan L, Castellon SA, Mallam S, Cheng I, Ahn R, Breen EC, Irwin MR, Silverman DHS (2013) The association between pro-inflammatory cytokines, regional cerebral metabolism, and cognitive complaints following adjuvant chemotherapy for breast cancer. Brain Imaging Behav 7:511-523

91. Silverman DHS, Dy CJ, Castellon SA, Lai J, Pio BS, Abraham L, Waddell K, Petersen L, Phelps ME, Ganz PA (2007) Altered frontocortical, cerebellar, and basal ganglia activity in adjuvanttreated breast cancer survivors 5-10 years after chemotherapy. Breast Cancer Res Treat 103:303-311

92. Ponto LLB, Menda Y, Magnotta VA, Yamada TH, Denburg NL, Schultz SK (2015) Frontal hypometabolism in elderly breast cancer survivors determined by [18F]fluorodeoxyglucose (FDG) positron emission tomography (PET): a pilot study. Int J Geriatr Psychiatry 30:587-594

93. Vitor T, Kozasa EH, Bressan RA, Lacerda SS, Campos Neto GC, Batista IR, Gebrim LH, Cohen L, Amaro E, Felicio AC (2019) Impaired brain dopamine transporter in chemobrain patients submitted to brain SPECT imaging using the technetium-99m labeled tracer TRODAT-1. Ann Nucl Med 33:269-279

94. Schroyen G, Blommaert J, van Weehaeghe D, Sleurs C, Vandenbulcke M, Dedoncker N, Hatse S, Goris A, Koole M, Smeets A, van Laere K, Sunaert S, Deprez S (2021) Neuroinflammation and its association with cognition, neuronal markers and peripheral inflammation after chemotherapy for breast cancer. Cancers (Basel). https://doi.org/10.3390/cancers13164198

95. Shrot S, Abebe-Campino G, Toren A, Ben-Haim S, Hoffmann C, Davidson T (2019) Fluorodeoxyglucose detected changes in brain metabolism after chemotherapy in pediatric non-hodgkin lymphoma. Pediatr Neurol 92:37-42

96. Sorokin J, Saboury B, Ahn JA, Moghbel M, Basu S, Alavi A (2014) Adverse functional effects of chemotherapy on wholebrain metabolism. Clin Nucl Med 39:e35-e39

97. Carideo L, Minniti G, Mamede M, Scaringi C, Russo I, Scopinaro F, Cicone F (2018) 18F-DOpA uptake parameters in glioma: effects of patients' characteristics and prior treatment history. $\mathrm{Br}$ J Radiol. https://doi.org/10.1259/bjr.20170847

98. Lin A, Andronesi O, Bogner W, Choi I, Coello E, Cudalbu C, Juchem C, Kemp GJ, Kreis R, Krššák M, Lee P, Maudsley AA, Meyerspeer M, Mlynarik V, Near J, Öz G, Peek AL, Puts NA, Ratai E, Tkáč I, Mullins PG (2021) Minimum Reporting Standards for in vivo Magnetic Resonance Spectroscopy (MRSinMRS): experts' consensus recommendations. NMR Biomed. https://doi.org/10.1002/nbm.4484

99. Wilson M, Andronesi O, Barker PB, Bartha R, Bizzi A, Bolan PJ, Brindle KM, Choi I, Cudalbu C, Dydak U, Emir UE, Gonzalez RG, Gruber S, Gruetter R, Gupta RK, Heerschap A, Henning A, Hetherington HP, Huppi PS, Hurd RE, Kantarci K, Kauppinen RA, Klomp DWJ, Kreis R, Kruiskamp MJ, Leach MO, Lin AP, Luijten PR, Marjańska M, Maudsley AA, Meyerhoff DJ, Mountford CE, Mullins PG, Murdoch JB, Nelson SJ, Noeske R, Öz G, Pan JW, Peet AC, Poptani H, Posse S, Ratai E, Salibi N, Scheenen TWJ, Smith ICP, Soher BJ, Tkáč I, Vigneron DB, Howe FA (2019) Methodological consensus on clinical proton MRS of the brain: review and recommendations. Magn Reson Med 82:527-550

100. Ernst T (2002) The effects of tamoxifen and estrogen on brain metabolism in elderly women. CancerSpectrum Knowl Environ 94:592-597

101. Graf C, MacMillan EL, Fu E, Harris T, Traboulsee A, Vavasour IM, MacKay AL, Mädler B, Li DKB, Laule C (2019) Intra- and inter-site reproducibility of human brain single-voxel proton MRS at 3 T. NMR Biomed 32:e4083

102. van de Bank BL, Emir UE, Boer VO, van Asten JJA, Maas MC, Wijnen JP, Kan HE, Oz G, Klomp DWJ, Scheenen TWJ (2015) Multi-center reproducibility of neurochemical profiles in the human brain at 7 T. NMR Biomed 28:306-316

103. Lodge MA (2017) Repeatability of SUV in oncologic 18 F-FDG PET. J Nucl Med 58:523-532

104. Hofheinz F, Apostolova I, Oehme L, Kotzerke J, van den Hoff J (2017) Test-retest variability in lesion SUV and lesion SUR in 18 F-FDG PET: an analysis of data from two prospective multicenter trials. J Nucl Med 58:1770-1775

105. Zhang H, Schneider T, Wheeler-Kingshott CA, Alexander DC (2012) NODDI: practical in vivo neurite orientation dispersion and density imaging of the human brain. Neuroimage 61:1000-1016 
106. Steven AJ, Zhuo J, Melhem ER (2014) Diffusion kurtosis imaging: an emerging technique for evaluating the microstructural environment of the brain. Am J Roentgenol 202:W26-W33

107. Fukutomi H, Glasser MF, Murata K, Akasaka T, Fujimoto K, Yamamoto T, Autio JA, Okada T, Togashi K, Zhang H, Van Essen DC, Hayashi T (2019) Diffusion tensor model links to neurite orientation dispersion and density imaging at high b-value in cerebral cortical gray matter. Sci Rep 9:12246

108. Van Cauter S, Veraart J, Sijbers J, Peeters RR, Himmelreich U, De Keyzer F, Van Gool SW, Van Calenbergh F, De Vleeschouwer S, Van Hecke W, Sunaert S (2012) Gliomas: diffusion kurtosis MR imaging in grading. Radiology 263:492-501

109. Ruetten PPR, Gillard JH, Graves MJ (2019) Introduction to quantitative susceptibility mapping and susceptibility weighted imaging. Br J Radiol 92:20181016

110. Lee J, Hyun J, Lee J, Choi E, Shin H, Min K, Nam Y, Kim HJ, Oh S (2021) So you want to image myelin using MRI: an overview and practical guide for myelin water imaging. J Magn Reson Imaging 53:360-373

111. Alonso-Ortiz E, Levesque IR, Pike GB (2015) MRI-based myelin water imaging: a technical review. Magn Reson Med 73:70-81

112. Schmierer K, Tozer DJ, Scaravilli F, Altmann DR, Barker GJ, Tofts PS, Miller DH (2007) Quantitative magnetization transfer imaging in postmortem multiple sclerosis brain. J Magn Reson Imaging 26:41-51

113. Romero-Garcia R, Suckling J, Owen M, Assem M, Sinha R, Coelho P, Woodberry E, Price SJ, Burke A, Santarius T, Erez Y, Hart MG (2021) Memory recovery in relation to default mode network impairment and neurite density during brain tumor treatment. J Neurosurg. https://doi.org/10.3171/2021.1.JNS203959

114. Chakhoyan A, Woodworth DC, Harris RJ, Lai A, Nghiemphu PL, Liau LM, Pope WB, Cloughesy TF, Ellingson BM (2018) Mono-exponential, diffusion kurtosis and stretched exponential diffusion MR imaging response to chemoradiation in newly diagnosed glioblastoma. J Neurooncol 139:651-659

115. Billiet T, Emsell L, Vandenbulcke M, Peeters R, Christiaens D, Leemans A, Van Hecke W, Smeets A, Amant F, Sunaert S, Deprez S (2018) Recovery from chemotherapy-induced white matter changes in young breast cancer survivors? Brain Imaging Behav 12:64-77

116. Wu G, Li R-r, Balasubramanian PS, Li M-m, Yang K, Huang W-y, Chen F (2020) Temporal lobe microstructural abnormalities in patients with nasopharyngeal carcinoma quantitatively evaluated by high-resolution DWI and DKI after concurrent chemoradiotherapy. Clin Transl Radiat Oncol 21:36-43

117. Tso WWY, Hui ESK, Lee TMC, Liu APY, Ip P, Vardhanabhuti V, Cheng KKF, Fong DYT, Chang DHF, Ho FKW, Yip KM, Ku DTL, Cheuk DKL, Luk CW, Shing MK, Leung LK, Khong PL, Chan GCF (2021) Brain microstructural changes associated with neurocognitive outcome in intracranial germ cell tumor survivors. Front Oncol 11:1-9

118. Stouten-Kemperman MM, de Ruiter MB, Caan MWA, Boogerd W, Kerst MJ, Reneman L, Schagen SB (2015) Lower cognitive performance and white matter changes in testicular cancer survivors 10 years after chemotherapy. Hum Brain Mapp 36:4638-4647

119. Sleurs C, Lemiere J, Christiaens D, Billiet T, Peeters R, Sunaert S, Uyttebroeck A, Deprez S (2018) Advanced MR diffusion imaging and chemotherapy-related changes in cerebral white matter microstructure of survivors of childhood bone and soft tissue sarcoma? Hum Brain Mapp 39:3375-3387

120. Chen BT, Ghassaban K, Jin T, Patel SK, Ye N, Sun CL, Kim H, Rockne RC, Mark Haacke E, Root JC, Saykin AJ, Ahles TA, Holodny AI, Prakash N, Mortimer J, Waisman J, Yuan Y, Somlo G, Li D, Yang R, Tan H, Katheria V, Morrison R, Hurria A (2018) Subcortical brain iron deposition and cognitive performance in older women with breast cancer receiving adjuvant chemotherapy: a pilot MRI study. Magn Reson Imaging 54:218-224

121. Cushing CM, Petronek MS, Bodeker KL, Vollstedt S, Brown HA, Opat E, Hollenbeck NJ, Shanks T, Berg DJ, Smith BJ, Smith MC, Monga V, Furqan M, Howard MA, Greenlee JD, Mapuskar KA, St-Aubin J, Flynn RT, Cullen JJ, Buettner GR, Spitz DR, Buatti JM, Allen BG, Magnotta VA (2021) Magnetic resonance imaging (MRI) of pharmacological ascorbate-induced iron redox state as a biomarker in subjects undergoing radio-chemotherapy. Redox Biol 38:101804

122. Mehrabian H, Myrehaug S, Soliman H, Sahgal A, Stanisz GJ (2018) Quantitative magnetization transfer in monitoring glioblastoma (GBM) response to therapy. Sci Rep 8:1-11

123. Steen RG, Koury BSM, Granja CI, Xiong X, Wu S, Glass JO, Mulhern RK, Kun LE, Merchant TE (2001) Effect of ionizing radiation on the human brain: white matter and gray matter $\mathrm{T} 1$ in pediatric brain tumor patients treated with conformal radiation therapy. Int J Radiat Oncol Biol Phys 49:79-91

124. Lehmann N, Aye N, Kaufmann J, Heinze H-J, Düzel E, Ziegler G, Taubert M (2021) Longitudinal reproducibility of neurite orientation dispersion and density imaging (NODDI) derived metrics in the white matter. Neuroscience 457:165-185

125. Shahim P, Holleran L, Kim JH, Brody DL (2017) Test-retest reliability of high spatial resolution diffusion tensor and diffusion kurtosis imaging. Sci Rep 7:11141

126. Wu G, Luo SS, Balasubramanian PS, Dai GM, Li RR, Huang WY, Chen F (2020) Early stage markers of late delayed neurocognitive decline using diffusion kurtosis imaging of temporal lobe in nasopharyngeal carcinoma patients. J Cancer 11:6168-6177

127. Alsop DC, Detre JA, Golay X, Günther M, Hendrikse J, Hernandez-Garcia L, Lu H, MacIntosh BJ, Parkes LM, Smits M, van Osch MJPP, Wang DJJJ, Wong EC, Zaharchuk G (2015) Recommended implementation of arterial spin-labeled perfusion MRI for clinical applications: a consensus of the ISMRM perfusion study group and the European consortium for ASL in dementia. Magn Reson Med 73:102-116

128. Mutsaerts HJMM, Petr J, Groot P, Vandemaele P, Ingala S, Robertson AD, Václavů L, Groote I, Kuijf H, Zelaya F, O’Daly O, Hilal S, Wink AM, Kant I, Caan MWA, Morgan C, de Bresser J, Lysvik E, Schrantee A, Bjørnebekk A, Clement P, Shirzadi Z, Kuijer JPA, Wottschel V, Anazodo UC, Pajkrt D, Richard E, Bokkers RPH, Reneman L, Masellis M, Günther M, MacIntosh BJ, Achten E, Chappell MA, van Osch MJP, Golay X, Thomas DL, De Vita E, Bjørnerud A, Nederveen A, Hendrikse J, Asllani I, Barkhof F (2020) ExploreASL: an image processing pipeline for multi-center ASL perfusion MRI studies. Neuroimage 219:117031

129. Boxerman JL, Quarles CC, Hu LS, Erickson BJ, Gerstner ER, Smits M, Kaufmann TJ, Barboriak DP, Huang RH, Wick W, Weller M, Galanis E, Kalpathy-Cramer J, Shankar L, Jacobs P, Chung C, van den Bent MJ, Chang S, Al Yung WK, Cloughesy TF, Wen PY, Gilbert MR, Rosen BR, Ellingson BM, Schmainda KM, Arons DF, Kingston A, Sandak D, Wallace M, Musella A, Haynes C (2020) Consensus recommendations for a dynamic susceptibility contrast MRI protocol for use in high-grade gliomas. Neuro Oncol 22:1262-1275

130. Bannier E, Barker G, Borghesani V, Broeckx N, Clement P, Emblem KE, Ghosh S, Glerean E, Gorgolewski KJ, Havu M, Halchenko YO, Herholz P, Hespel A, Heunis S, Hu Y, Hu C, Huijser D, Iglesia Vayá M, Jancalek R, Katsaros VK, Kieseler M, Maumet C, Moreau CA, Mutsaerts H, Oostenveld R, OzturkIsik E, Pascual Leone Espinosa N, Pellman J, Pernet CR, Pizzini FB, Trbalić AŠ, Toussaint P, di Oleggio V, Castello M, Wang F, Wang C, Zhu H (2021) The Open Brain Consent: informing 
research participants and obtaining consent to share brain imaging data. Hum Brain Mapp 42:1945-1951

131. Gorgolewski KJ, Auer T, Calhoun VD, Craddock RC, Das S, Duff EP, Flandin G, Ghosh SS, Glatard T, Halchenko YO, Handwerker DA, Hanke M, Keator D, Li X, Michael Z, Maumet C, Nichols BN, Nichols TE, Pellman J, Poline J-B, Rokem A, Schaefer G, Sochat V, Triplett W, Turner JA, Varoquaux G, Poldrack RA (2016) The brain imaging data structure, a format for organizing and describing outputs of neuroimaging experiments. Sci Data 3:160044

132. Norgaard M, Matheson GJ, Hansen HD, Thomas A, Searle G, Rizzo G, Veronese M, Giacomel A, Yaqub M, Tonietto M, Funck T, Gillman A, Boniface H, Routier A, Dalenberg JR, Betthauser T, Feingold F, Markiewicz CJ, Gorgolewski KJ, Blair RW, Appelhoff S, Gau R, Salo T, Niso G, Pernet C, Phillips C, Oostenveld R, Gallezot J-D, Carson RE, Knudsen GM, Innis RB, Ganz M (2021) PET-BIDS, an extension to the brain imaging data structure for positron emission tomography. bioRxiv. https:// doi.org/10.1101/2021.06.16.448390

133. Clement P, Castellaro M, Okell TW, Thomas DL, Vandemaele P, Elgayar S, Oliver-Taylor A, Kirk T, Woods JG, Vos S, Kuijer JPA, Achten E, van Osch MJP, Gau R, Detre J, Lu H, Alsop DC, Chappell MA, Hernandez-Garcia L, Petr J, Mutsaerts HJ (2021) ASL-BIDS, the brain imaging data structure extension for arterial spin labeling. PsyArXiv. https://doi.org/10.31234/ osf.io/e $87 \mathrm{y} 3$

134. Bell LC, Semmineh N, An H, Eldeniz C, Wahl R, Schmainda KM, Prah MA, Erickson BJ, Korfiatis P, Wu C, Sorace AG, Yankeelov TE, Rutledge N, Chenevert TL, Malyarenko D, Liu Y, Brenner A, Hu LS, Zhou Y, Boxerman JL, Yen Y-F, KalpathyCramer J, Beers AL, Muzi M, Madhuranthakam AJ, Pinho M, Johnson B, Quarles CC (2020) Evaluating the use of rCBV as a tumor grade and treatment response classifier across NCI quantitative imaging network sites: part II of the DSC-MRI digital reference object (DRO) challenge. Tomography 6:203-208

135. Smits M, Bendszus M, Collette S, Postma LA, Dhermain F, Hagenbeek RE, Clement PM, Liu Y, Wick W, van den Bent MJ, Heiland S (2019) Repeatability and reproducibility of relative cerebral blood volume measurement of recurrent glioma in a multicentre trial setting. Eur J Cancer 114:89-96

136. Markiewicz CJ, Gorgolewski KJ, Feingold F, Blair R, Halchenko YO, Miller E, Hardcastle N, Wexler J, Esteban O, Goncalves M, Jwa A, Poldrack RA (2021) OpenNeuro: an open resource for sharing of neuroimaging data. BioRxiv. https://doi.org/10.1101/ 2021.06.28.450168

137. Le Bihan D (2019) What can we see with IVIM MRI? Neuroimage 187:56-67

138. Jack CR, Knopman DS, Jagust WJ, Shaw LM, Aisen PS, Weiner MW, Petersen RC, Trojanowski JQ (2010) Hypothetical model of dynamic biomarkers of the Alzheimer's pathological cascade. Lancet Neurol 9:119-128

139. Iturria-Medina Y, Sotero RC, Toussaint PJ, Mateos-Pérez JM, Evans AC (2016) Early role of vascular dysregulation on lateonset Alzheimer's disease based on multifactorial data-driven analysis. Nat Commun 7:11934

140. Petr J, Platzek I, Seidlitz A, Mutsaerts HJMM, Hofheinz F, Schramm G, Maus J, Beuthien-Baumann B, Krause M, van den Hoff J (2016) Early and late effects of radiochemotherapy on cerebral blood flow in glioblastoma patients measured with non-invasive perfusion MRI. Radiother Oncol 118:24-28

Publisher's Note Springer Nature remains neutral with regard to jurisdictional claims in published maps and institutional affiliations.

\title{
Authors and Affiliations
}

\author{
Jan Petr ${ }^{1,2}\left(\right.$ - Louise Hogeboom ${ }^{2} \cdot$ Pavel Nikulin $^{1} \cdot$ Evita Wiegers $^{3} \cdot$ Gwen Schroyen $^{4} \cdot$ Jesper Kallehauge $^{5}$. \\ Marek Chmelík $^{6}$. Patricia Clement ${ }^{7}$. Ruben E. Nechifor ${ }^{8} \cdot$ Liviu-Andrei Fodor $^{9}$. Philip C. De Witt Hamer ${ }^{10}$. \\ Frederik Barkhof $^{2,11} \cdot$ Cyril Pernet $^{12} \cdot$ Maarten Lequin $^{3} \cdot$ Sabine Deprez ${ }^{4} \cdot$ Radim Jančálek $^{13}$. \\ Henk J. M. M. Mutsaerts ${ }^{2,7} \cdot$ Francesca B. Pizzini $^{14} \cdot$ Kyrre E. Emblem $^{15} \cdot$ Vera C. Keil $^{2}$
}

$1 \quad$ Helmholtz-Zentrum Dresden-Rossendorf, Institute of Radiopharmaceutical Cancer Research, Dresden, Germany

2 Department of Radiology and Nuclear Medicine, Amsterdam UMC, Amsterdam Neuroscience, Amsterdam, The Netherlands

3 Department of Radiology, University Medical Center Utrecht, Utrecht, The Netherlands

4 Department of Imaging and Pathology, KU Leuven, Leuven, Belgium

5 Danish Center for Particle Therapy, Aarhus University Hospital, Aarhus, Denmark

6 Department of Technical Disciplines in Medicine, Faculty of Health Care, University of Prešov, Prešov, Slovakia

7 Ghent Institute for Functional and Metabolic Imaging (GIfMI), Ghent University, Ghent, Belgium

8 International Institute for the Advanced Studies of Psychotherapy and Applied Mental Health, Department of Clinical Psychology and Psychotherapy, Babeș-Bolyai University, Cluj-Napoca, Romania

9 International Institute for the Advanced Studies of Psychotherapy and Applied Mental Health, Evidence Based Psychological Assessment and Interventions Doctoral School, Babeș-Bolyai University, Cluj-Napoca, Romania

10 Department of Neurosurgery, Amsterdam UMC, Amsterdam Neuroscience, Amsterdam, The Netherlands

11 UCL Queen Square Institute of Neurology, University College London, London, UK

12 Neurobiology Research Unit, Copenhagen University Hospital, Rigshospitalet, Denmark

13 St. Anne's University Hospital Brno and Faculty of Medicine, Masaryk University, Brno, Czech Republic

14 Radiology, Deptartment of Diagnostic and Public Health, Verona University, Verona, Italy

15 Department of Diagnostic Physics, Division of Radiology and Nuclear Medicine, Oslo University Hospital, Oslo, Norway 